\title{
Resveratrol and Its Oligomers: Modulation of Sphingolipid Metabolism and Signaling in Disease
}

Keng Gat Lim ${ }^{\ddagger *}$, Alexander I. Gray ${ }^{\ddagger}$, Nahoum G. Anthony $y^{\ddagger}$, Simon P. Mackay ${ }^{\ddagger}$, Susan Pyne ${ }^{\ddagger}$ and Nigel J. Pyne

Cell Biology and Drug Discovery \& Design Groups, Strathclyde Institute of Pharmacy and Biomedical Sciences, University of Strathclyde, Glasgow G4 0RE, United Kingdom

/ Current address: Cancer Therapeutics \& Stratified Oncology, Genome Institute of Singapore, Agency for

Science, Technology, and Research (A*STAR), Biopolis, Singapore 138672, Singapore

* To whom correspondence should be addressed 


\section{Content}

1. Introduction

1.1. Origin and activity of resveratrol oligomers

1.2. Resveratrol oligomerization

1.3. Pharmacokinetics and toxicity

2. Sphingolipids

2.1. Sphingolipid metabolism

2.2. Biological activity of sphingolipids

2.3. S1P signaling

3. Effects of resveratrol on sphingolipids in disease

3.1. Cancer and inflammation

3.2. Cardiovascular disease

3.3. Neurodegenerative disease

3.4. Metabolic disease

4. Summary and future directions 


\begin{abstract}
Resveratrol, a natural compound endowed with multiple health-promoting effects has received much attention given its potential for the treatment of cardiovascular, inflammatory, neurodegenerative, metabolic and age-related diseases. However, the translational potential of resveratrol has been limited by its specificity, poor bioavailability and uncertain toxicity. In recent years, there has been an accumulation of evidence demonstrating that resveratrol modulates sphingolipid metabolism. Moreover, resveratrol forms higher order oligomers that exhibit better selectivity and potency in modulating sphingolipid metabolism. This review evaluates the evidence supporting the modulation of sphingolipid metabolism and signaling as a mechanism of action underlying the therapeutic efficacy of resveratrol and oligomers in diseases, such as cancer.
\end{abstract}




\section{Introduction}

First isolated in the 1940s, resveratrol (3,4',5-trihydroxy-trans-stilbene) received little attention until 50 years later when it was found to be a major ingredient in red wine and identified as a chemo-preventive agent (Baur and Sinclair 2006). It is no surprise that resveratrol has been dubbed the "elixir of eternal youth" in view of its beneficial effects in preventing or slowing the progression of many human diseases by mediating cardiovascular protection, modulating lipoprotein metabolism and extending lifespan with its anti-inflammatory, anti-oxidant, anti-cancer and anti-aging properties (Orallo 2008). Despite advances in the field with evidence obtained from preclinical models, it is hard to comprehend how a simple molecule like resveratrol could act on a vast number of targets. Recently, several phytochemicals including resveratrol have been shown to inhibit membrane proteins non-specifically through perturbation of the lipid bilayer (Ingolfsson et al. 2014). In addition, many distal targets of resveratrol have been found but few studies have identified direct binding partners of resveratrol.

Using techniques such as X-ray crystallography, computer simulation and modeling, affinity chromatography, nuclear magnetic resonance studies, biochemical and biophysical analyses, several bona fide resveratrol binding targets have been characterized. These include sirtuin 1 (Sinclair and Guarente 2014), estrogen receptor $\alpha$ (Nwachukwu et al. 2014), cAMP phosphodiesterases (Park et al. 2012), cardiac protein troponin C (Pineda-Sanabria et al. 2011), leukotriene $\mathrm{A}_{4}$ hydrolase (Oi et al. 2010), cyclooxygenase 1 and 2 (Szewczuk et al. 2004; Zykova et al. 2008), F1-ATPase (Gledhill et al. 2007) and quinine reductase 2 (Buryanovskyy et al. 2004). These biological targets link resveratrol to its pleiotropic effects such as lifespan extension, cardio-protection and chemoprevention. Another possibility for polypharmacology might be that, like a 'butterfly effect', resveratrol perturbs the activity of certain signaling molecules that regulate diverse functions in cellular homeostasis. Indeed, resveratrol is known to act on critical nodes in various signaling pathways including the phosphatidylinositol 3-kinase/Akt/mammalian target of rapamycin (PI3K/Akt/mTOR) pathway (Widlund et al. 2013), estrogen signaling (Mobasheri and Shakibaei 2013; Signorelli and Ghidoni 2005), AMP-activated protein kinase/sirtuin 1/peroxisome proliferator-activated receptor gamma coactivator 1-alpha (AMPK/SIRT1/PGC-1 $\alpha$ ) pathway (Baur et al. 2012; Canto and Auwerx 2012) and stress-induced NF-kB signaling (Gupta et al. 2014; Wu et al. 2013). 
Sphingolipids constitute one of the major classes of lipids in cells with diverse effects in regulating cellular processes, such as proliferation, survival, migration, differentiation and angiogenesis. Accumulating evidence suggests that some of the pharmacological activities of resveratrol are, in part, mediated through changes in sphingolipid metabolism. Moreover, resveratrol forms many bioactive oligomers, although these are less well characterized. This review aims to update the reader about the biological activity of resveratrol and to provide a current understanding of its effects on sphingolipid metabolism and signaling. Evidence will be presented for enhanced selectivity or potency of resveratrol oligomers. We will also discuss the therapeutic roles of resveratrol with respect to sphingolipid biology in various disease states.

\subsection{Origin and activity of resveratrol oligomers}

Resveratrol, produced in plants, belongs to a class of secondary metabolites known as stilbenoids that consist of two phenol rings linked together with an ethylene bridge (Fig. 1). The dietary source and activity of resveratrol have been extensively studied and reviewed (Baur and Sinclair 2006; Burns et al. 2002; Shukla and Singh 2011). Nevertheless, resveratrol can oligomerize to form oligostilbenoids in diverse plant families such as Dipterocarpaceae, Vitaceae, Leguminosae, Cyperaceae, and Gnetaceae (Sotheeswaran and Pasupathy 1993). Here we focus on resveratrol and its oligomers produced by plants in the Dipterocarpaceae, Hopea genus. Dipterocarpaceae is a well-known family of rainforest trees, which consist of approximately 500 species with greater than 100 species in the Hopea genus distributed mainly in tropical countries (Dayanandan et al. 1999). Selected resveratrol oligomers are presented in Fig. 1 to show the complexity achieved by natural oligomerization. A common biosynthetic route of these resveratrol oligomers has been proposed (Sotheeswaran and Pasupathy 1993) but their isolation from natural products has been a daunting task and it is not until recently that total synthesis has become feasible ( $\underline{\text { Snyder et al. }}$ 2011). 

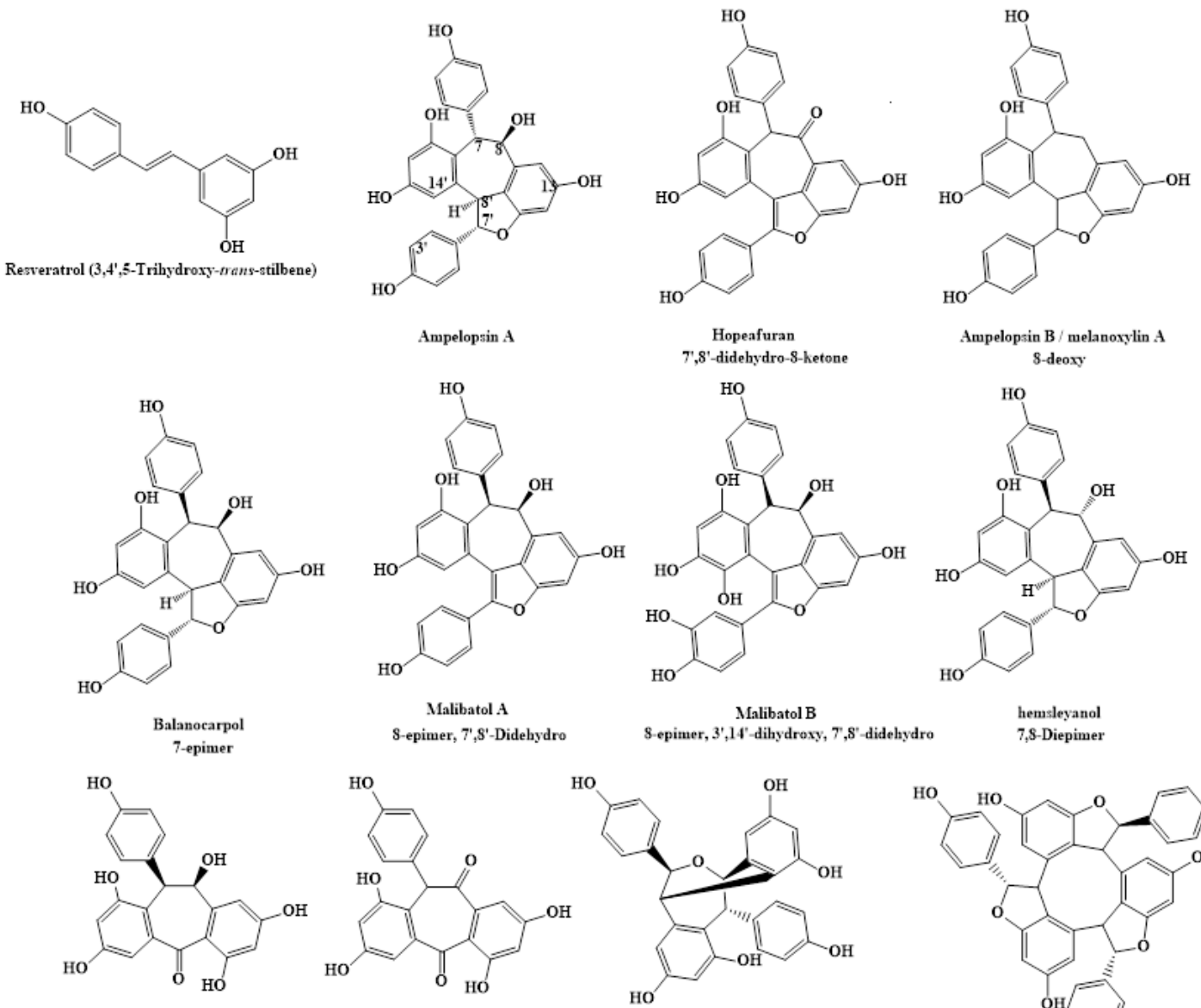

$$
\begin{aligned}
& \text { hemsleyanol } \\
& \text { 7,8-Diepimer }
\end{aligned}
$$
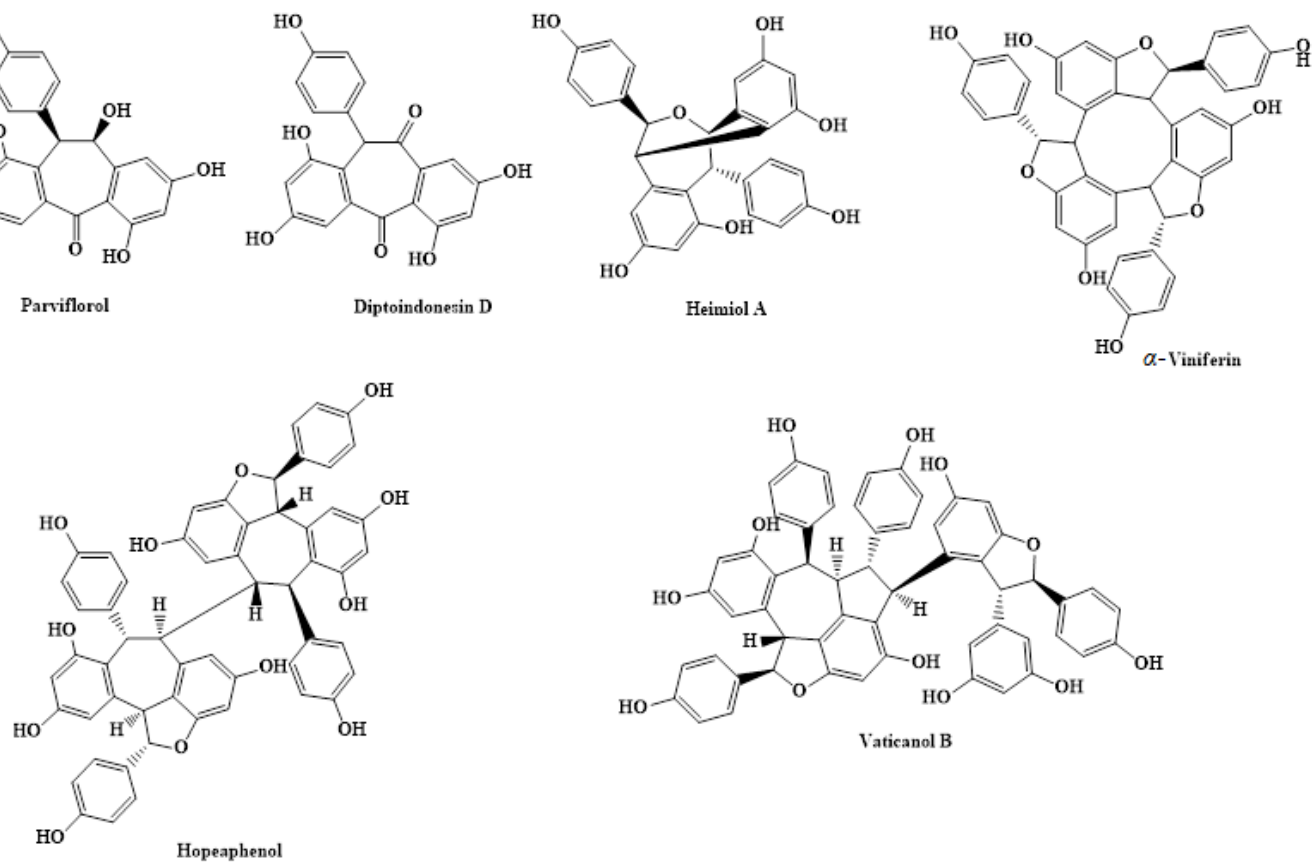

Figure 1. Representative structures of resveratrol and its oligomers isolated from Hopea dryobalanoides. Relative stereochemistry of each molecule is indicated. 


\section{Resveratrol tetramers}

Hopeaphenol, a resveratrol tetramer, was one of the first compounds isolated from Hopea odorata and its structure confirmed by X-ray crystallography (Coggon et al. 1965; Coggon et al. 1966). Later, this compound was purified from other species in the same genus including Hopea dryobalanoides, Hopea malibato and Hopea parviflora (Dai et al. 1998; Sahidin et al. 2005; Tanaka et al. 2000). Interestingly, hopeaphenol has also been found in other plant genera including Neobalanocarpus heimii, Dipterocarpus hasseltii and Vitis vinifera (Muhtadi et al. 2006; Weber et al. 2001; Yan et al. 2001) suggesting its common existence as an important secondary metabolite. Hopeaphenol has strong growth inhibitory action against several cancer cells, such as human epidermoid nasopharynx carcinoma (KB), lung cancer carcinoma (A549), breast cancer (MCF-7) and murine leukaemia cells (P-388) (Muhtadi et al. 2006; Ohyama et al. 1999). Hopeaphenol also exhibits moderate anti-microbial activity against Mycobacterium smegmatis and methicillin-resistant Staphylococcus aureus (Zgoda-Pols et al. 2002). More recently, hopeaphenol has been found to block the type III secretion system essential for pathogenicity of gram negative bacteria, suggesting a selective inhibition of bacterial virulence (Zetterstrom et al. 2013). Taken together, hopeaphenol is one of the most active compounds produced by tropical trees. However, its mechanisms of action and direct protein targets remain to be elucidated. Vaticanol B is another resveratrol tetramer isolated from Hopea dryobalanoides and has been shown to moderately inhibit P-388 cell growth (Muhtadi et al. 2006; Sahidin et al. 2005). Vaticanol B has weaker growth inhibitory action compared with hopeaphenol, but exhibits anti-inflammatory effects that protect cells from ER-stress by inhibiting the activation of the unfolded protein response (UPR) genes (Tabata et al. 2007). Vaticanol C (an isomer of vaticanol B) induces apoptosis in various human cancer cell lines and a mouse mammary tumor model by perturbing mitochondrial membrane potential, activating pro-apoptotic proteins, such as caspases and Bad, down-regulating pro-survival signaling molecules, such as BCL2 and inhibiting ERK and Akt signaling pathways (Ito et al. 2002; Ito et al. 2003; Ohguchi et al. 2005; Shibata et al. 2007). Further investigations are needed to assess the pharmacokinetics of vaticanol $\mathrm{C}$ and potential toxicity in view of its therapeutic potential as an anti-cancer agent. 


\section{Resveratrol trimers}

$\alpha$-viniferin is a resveratrol trimer isolated from grapes of the common grape vine (Vitis vinifera) and exhibits anti-fungal activity (Langcake and Pryce 1977a). Interestingly, resveratrol, $\varepsilon$-viniferin (dimer) and $\alpha$-viniferin (trimer) have been produced successively in a time-dependent manner under UV irradiation, indicating that the biosynthetic precursor is indeed, the resveratrol monomer (Langcake and Pryce 1977b). Similar to other resveratrol oligomers, $\alpha$-viniferin inhibits cancer cell growth but fails to induce apoptosis of colon cancer cells (Gonzalez-Sarrias et al. 2011). $\alpha$-viniferin suppresses interferon- $\gamma$-induced inflammation in mouse macrophages by down-regulating signal transducer and activators of transcription 1 (STAT1)-inducible inflammatory proteins, such as inducible NO synthase (iNOS), interferon- $\gamma$-inducible protein-10 (IP10) and monokine-induced by interferon- $\gamma$ (MIG) (Chung et al. 2010). $\alpha$-viniferin also reduces both early and late stages of LPS-induced inflammation in BV2 microglial cells through inhibition of PI3K/Akt-dependent NF- $\mathrm{kB}$ activation, reduced formation of pro-inflammatory molecules such as nitric oxide and prostaglandin E2 and suppression of nuclear factor erythroid 2-related factor 2 (Nrf2)- mediated haem oxygenase-1 expression (Dilshara et al. 2014). In vitro enzyme assays shows that $\alpha$-viniferin has favorable anti-cholinesterase activity that might be useful for the treatment of Alzheimer's disease (Pinho et al. 2013; Sung et al. 2002; Yan et al. 2012). $\alpha$-viniferin also exhibits activity against serotonin (5-HT 6 ) receptor (Kim et al. 2010), DNA topoisomerase II (Yamada et al. 2006), multidrug resistance-associated protein 1 (MRP1/ABCC1) (Bobrowska-Hagerstrand et al. 2006), COX-1 (Lee et al. 1998), COX-2 (Chung

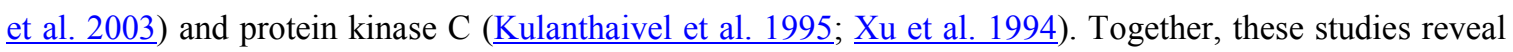
an interesting insight into the mechanism of action of $\alpha$-viniferin. This resveratrol trimer not only interacts with a large number of targets (estimated to be as diverse as resveratrol) but also has improved potency and may selectively access other biological targets with an "optimal" structure (see section 1.2 for discussion on resveratrol oligomerization). However, compared to the number of studies dedicated to resveratrol, fewer investigations have focused on $\alpha$-viniferin. Future studies using animal models are needed to examine the physiological and therapeutic relevance of these targets since all studies cited above have only assessed $\alpha$-viniferin in vitro. 


\section{Resveratrol dimers}

Parviflorol, diptoindonesin D, balanocarpol, heimiol A and hopeafuran are examples of resveratrol dimers isolated from Hopea dryobalanoides (Sahidin et al. 2005). Parviflorol was first isolated from Hopea parviflora as a yellow solid and has moderate growth-inhibitory activity in cancer (Sahidin et al. 2005; Tanaka et al. 2000). Diptoindonesin D was subsequently isolated as a derivative (8-ketone) of parviflorol. Heimiol A was isolated as a light brown solid from Neobalanocarpus heimii (Weber et al. 2001). In fact, parviflorol and diptoindonesin D are modified dimers of resveratrol whereas balanocarpol and hopeafuran are derivatives of ampelopsin A (Fig. 1). Little information is available on the activities of these dimers. Notably, malibatol A and B isolated from Hopea malibato were found to be active against HIV in cultured human lymphoblastoid cells (Dai et al. 1998). Although balanocarpol shares similar structure with malibatol A and B, it has only modest activity against HIV. Kinetic inhibition studies establish that balanocarpol is a mixed competitive inhibitor (with sphingosine) of sphingosine kinase 1 (SK1) (Lim et al. 2012a). Despite successful isolation of resveratrol oligomers, further study has been hampered by low yield of these compounds and limited availability through total synthesis (Snyder et al. 2011). Conversely, resveratrol monomer is widely available and easily accessible; hence, is also extensively studied.

\section{Resveratrol monomer}

Several comprehensive reviews have been published concerning the in vitro and in vivo activities of resveratrol (Baur and Sinclair 2006; Signorelli and Ghidoni 2005; Widlund et al. 2013) . Therefore, a brief overview of its activity will be discussed here in relation to recent updates. Found abundantly in grapes and various dietary sources resveratrol has been isolated from over 70 plant species (Jang et al. 1997). Resveratrol is active against various human cancers as shown in cultured tumor cell and animal cancer models (Buryanovskyy et al. 2004). Anti-oxidant and anti-inflammatory effects were first proposed as the mechanisms for the anti-cancer and chemoprevention properties of resveratrol, which has phenol rings (strong scavengers of reactive oxygen species) and is able to inhibit COX-1 and COX-2 activities (Jang et al. 1997; Leonard et al. 2003; Subbaramaiah et al. 1998). 
The anti-cancer activity of resveratrol has also been linked to perturbation of sphingolipid metabolism. In particular, resveratrol stimulates ceramide synthesis to induce apoptosis in breast cancer cells ( $\underline{\text { Scarlatti et al. }}$ 2003). Resveratrol might also reduce the production of the pro-survival sphingolipid, sphingosine 1phosphate (S1P). For example, resveratrol inhibits the activation of SK1 by phospholipase D and reduces SK1 expression to suppress pro-survival signaling in prostate cancer cells (Brizuela et al. 2010). Using an in vitro enzyme activity assay, SK1 has been found to be directly inhibited by resveratrol and balanocarpol (Lim et al. 2012a). Moreover, balanocarpol is two-fold more potent than resveratrol, suggesting that dimerization increases binding affinity for SK1 (see section 1.2 and Fig. 2). In addition to catalytic inhibition, both resveratrol and balanocarpol also down-regulate SK1 expression (Lim et al. 2012a). Therefore, resveratrol suppresses cell growth and induces apoptosis possibly by modulating the balance of ceramide and S1P in cancer cells.

Intense interests on resveratrol is due to its famous link with the "French paradox" where Mediterranean residents who consume red wine apparently have lower incidence of cardiovascular-related death, suggesting that resveratrol provides cardioprotection (Fremont 2000). However, a recent study that followed 783 elderly individuals who regularly consumed diets rich in resveratrol has found no significant association between any health benefits and total urinary resveratrol metabolite, casting doubts on its health-promoting effects (Semba et al. 2014). It is important to note that red wine (Guebailia et al. 2006) and other diets (Baechler et al. 2014; Barthomeuf et al. 2006) also contain significant amount of resveratrol oligomers that might be responsible for some of the beneficial health effects.

Notably, several plant polyphenols having similar structural moieties (e.g. piceatannol and resveratrol) were found to modulate life span and aging by activating sirtuin 1 (SIRT 1) (Howitz et al. 2003). The life span of yeast (Saccharomyces cerevisiae) was extended by $70 \%$ at low micromolar concentrations of resveratrol and attributed to activation of sirtuins that stabilize ribosomal DNA repeats rather than its antioxidant activity (Howitz et al. 2003). Subsequently, resveratrol has been shown to have similar effects as calorie restriction in prolonging the lives of roundworms, fish, flies, bees and mice (fed on a high-fat diet), indicating an evolutionary conserved mechanism of SIRT1 in regulation of health and lifespan (Baur et al. 2012; Sinclair and Guarente 2014). However, resveratrol-induced activation of SIRT1 and its role in 
prolonging lifespan is controversial with divergent views on whether this is a direct effect. In vitro assays measuring the activation of SIRT1 by resveratrol has been found to be dependent on fluorogenic substrates, raising doubts on the robustness of the assay (Borra et al. 2005; Kaeberlein et al. 2005). A recent study by Park and colleagues also supports an indirect effect of resveratrol via inhibition of cAMP phosphodiesterases leading to activation of the AMPK/SIRT1 signaling pathway (Park et al. 2012). Despite these findings, resveratrol has been shown to bind to and activate SIRT1 directly via an allosteric mechanism ( dependent (Sinclair and Guarente 2014). A subset of low molecular weight chemicals with related stilbene scaffolds can also activate SIRT1 ( targets, it will be of interest to investigate whether resveratrol oligomers can activate SIRT1 and mimic lifeextending and health-promoting effects of calorie restriction.

\subsection{Resveratrol oligomerization}

Why would nature produce structurally diverse resveratrol oligomers? There are several possible explanations when looking at the evolution of conserved biosynthetic pathways. Indeed, two models have been proposed for the evolution of structurally-related natural compounds: target-based and diversity-based models (Fischbach and Clardy 2007). The first model consists of secondary metabolites that show high affinity for their respective biological targets and these molecules have evolved to improve host survival. For example, rapamycin (a polyketide) is an immunosuppressant that specifically inhibits FK-binding protein (FKBP-12) and mammalian target of rapamycin (mTOR) by forming a FKBP-12-rapamycin-mTOR complex (Choi et al. 1996). This elegant work demonstrates that rapamycin functions as a 'molecular glue' that simultaneously blocks downstream signaling of two different proteins. The second model posits that evolution favors the survival of organisms that can maximize the diversity of their secondary metabolites. For example, terpenes consist of a large group of organic compounds, all derived from a simple building block, the isoprene $\left(\mathrm{C}_{5} \mathrm{H}_{8}\right)$. At least 136 distinct gibberellin-family diterpenes are found in nature but only a few of them have potent biological effects; most are regarded as side products that lack activity (Fischbach and Clardy 2007). Therefore, certain secondary metabolites are synthesized in a diversity-oriented approach to maximize diversity and minimize metabolic cost by utilizing a common building block. In 
common with terpenes, resveratrol oligomerization is regarded as a diversity-oriented approach and evidence will be provided in the following to support this possibility.

Resveratrol oligomerization possibly arises through the need for improved potency and selectivity. Qiao and colleagues screened 31 resveratrol oligomers and found that several trimers and one tetramer are more effective than the monomers or dimers in suppressing growth of several human cancer cell lines (Table 1). These workers investigated the anti-tumor efficacy of pauciflorol B (trimer) in a murine tumor model and established p53-dependent apoptosis and cell senescence as the mechanisms of action (Qiao et al. 2013). Similarly, the rank of potency for growth inhibition in P-388 murine cancer cells is hopeaphenol (tetramer) > $\alpha$-viniferin (trimer) $>$ balanocarpol (dimer) (Sahidin et al. 2005). In addition, $\varepsilon$-viniferin (dimer) and miyabenol C (trimer) induced apoptosis in human myeloma U266 cells at lower concentrations than resveratrol (Barjot et al. 2007). Vaticanol $\mathrm{C}$ (tetramer) is also 4-7 fold more potent than resveratrol in killing SW480 and HL60 colon cancer cells (Ito et al. 2003). The anti-inflammatory activity is also increased with oligomerization since, vaticanol B (tetramer) is more active than resveratrol monomer and dimer (Tabata et al. 2007). Taken together, oligomerization improves the anti-cancer properties of resveratrol in terms of growth suppression and apoptosis.

Other cellular targets such as DNA topoisomerase II have been found to be more effectively inhibited by resveratrol oligomers (e.g. hopeaphenol) compared with the resveratrol monomer (Baechler et al. 2014). Interestingly, molecular size does not seem to be a constraint on the potency of higher order resveratrol oligomers since resveratrol hexamer still retains comparable activity compared with other tetramers against DNA topoisomerase II (Yamada et al. 2006). In the latter study, oligomers with higher repeating resveratrol units are also more active than smaller molecules (Table 1). In contrast, resveratrol is the most potent compound in inhibiting tyrosinase (an oxidase mediating the production of melanin) whereas modification of resveratrol by glucosidation (e.g. piceid), reduction (e.g. dihydroresveratrol) and oligomerization (e.g. $\alpha-$ viniferin) greatly reduces or abolishes activity against tyrosinase (huchi et al. 2003). $\alpha$-viniferin (trimer) inhibits cholinesterase (implicated in Alzheimer's disease) whereas resveratrol is not active at concentrations up to $500 \mu \mathrm{M}$ (Pinho et al. 2013). Moreover, $\alpha$-viniferin (trimer) is the most potent inhibitor of cholinesterase compared with the tetramer, kobophenol A (Sung et al. 2002). In addition, $\alpha$-viniferin is 
also 3-4-fold more potent than resveratrol at reducing prostaglandin H2 activity (Lee et al. 1998). $\alpha$ viniferin is also the most potent compound in blocking MRP1/ABCC1 activity whereas resveratrol is inactive (Bobrowska-Hagerstrand et al. 2006), indicating that some enzymes and proteins have strict steric and conformational requirements for resveratrol oligomers.

Another target of resveratrol oligomers is SK1, which catalyzes the phosphorylation of sphingosine to produce the bioactive lipid, S1P. S1P maintains cell survival and growth (Pyne and Pyne 2000) and is also involved in plant signaling (e.g. transpiration and seed germination) (Worrall et al. 2008). We found that balanocarpol (dimer) is more potent in inhibiting SK1 with an inhibition constant $\left(\mathrm{K}_{\mathrm{i}}\right)$ of $90 \pm 10 \mu \mathrm{M}$ compared with that for resveratrol of $160 \pm 40 \mu \mathrm{M}$. These findings suggest that dimerization increases potency against SK1 (Lim et al. 2012a). The molecular interactions of resveratrol and balanocarpol with SK1; the crystal structure having been recently resolved (Wang et al. 2013) have now been modeled by us (Fig. 2). The predicted binding mode of resveratrol shows that its hydroxyl groups forms hydrogen bonds with the backbone carbonyl of L268 and L299 and one of the side chain oxygens of D178 (the deprotonating base enabling nucleophilic attack by sphingosine on the $\gamma$-phosphate group of ATP) in the catalytic site of SK1. Due to increased size and number of hydroxyl groups (six in total), balanocarpol is modelled to bind to L268 and D178 but can form additional hydrogen bonds with the side chain oxygen of T196, the second carboxylate oxygen of D178 and the backbone carbonyl of A262. These modelling data can therefore provide an explanation for the increased potency of balanocarpol compared with resveratrol in inhibiting SK1 activity.

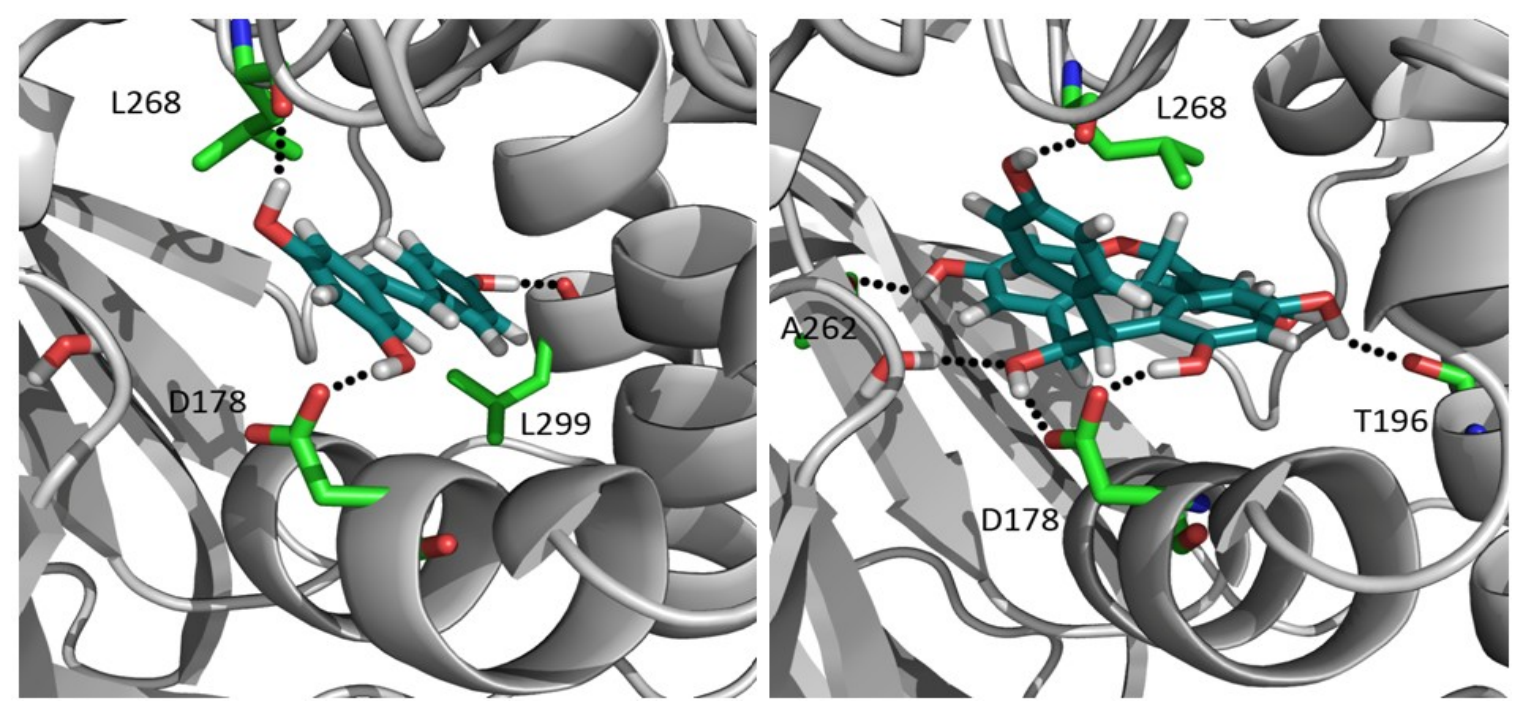


Figure 2. Binding modes obtained by docking resveratrol (left) and balanocarpol (right) in the sphingosine binding site of SK1 (PDB entry 3VZB). Chain A of the crystal structure of SK1 in complex with sphingosine was used to dock resveratrol and balanocarpol. The water molecule found to be tightly bound to the side chain $-\mathrm{OH}$ of $\mathrm{S} 168$, the backbone $-\mathrm{NH}$ of G342 and the secondary hydroxyl group of sphingosine is included in the modelling. Both compounds were docked using GOLD 5.2 for Windows (Cambridge Crystallographic Data Centre, Cambridge, UK), using default parameters and allowing the side chains of L259, L261, L263 and L302 to be freely flexible during the study. The flexibility of the sidechains of these leucines was required to allow the sphingosine binding site of SK1 to accommodate the bulky balanocarpol.

A distinct inhibitory profile has been documented for vitisin A and hopeaphenol, both of which are tetrameric forms of resveratrol. Unlike hopeahenol that consists of two repeating resveratrol dimers (ampelopsin B), vitisin A is a complex of one $\varepsilon$-viniferin and one ampelopsin B. Opposing effects were observed for vitisin A (pro-apoptotic) and hopeaphenol (anti-apoptotic) on calcium-induced cytochrome C release and mitochondrial depolarization in cardiac myocytes (Seya et al. 2009). Peroxisome proliferatoractivated receptors (PPAR, nuclear receptors that act as transcription factors) are also activated by resveratrol and vaticanol $\mathrm{C}$ (tetramer) but not $\varepsilon$-viniferin (dimer) (Tsukamoto et al. 2010). In addition, vaticanol $\mathrm{C}$ binds $\mathrm{PPAR}_{\alpha}$ and $\mathrm{PPAR}_{\beta / \delta}$, yet resveratrol stimulates all isoforms of PPAR. Interestingly, vaticanol C or $\varepsilon$-viniferin do not activate SIRT1 (Tsukamoto et al. 2010). Overall, these findings suggest that resveratrol oligomerization improves binding affinity (potency) and enhances target selectivity.

Polyphenols produced by plants might be used by animals as a signaling cue to improve survival when confronted by environmental stress (Howitz and Sinclair 2008). This hypothesis (termed xenohormesis) was supported by observations that a wide range of natural compounds interact with different signaling pathways in animals. In fact, the similarity between many signaling molecules in plants and animals indicates that common biosynthetic pathways existed before the two kingdoms diverged (Kushiro et al. 2003). A large amount of research over the past 20 years has shown that resveratrol not only serves specific roles in plant development and defense but can also target diverse signaling pathways in animals. The myriad biological functions of resveratrol might be explained by its simple, yet unique structure that has 
survived evolution. Thus, oligomerization provides a means to achieve better selectivity and potency to minimize metabolic cost. Further investigations of these compounds should provide impetus to fully develop the therapeutic potential of resveratrol. 
Table 1. Relative efficacies of representative resveratrol oligomers for different signaling molecules and pathways

\begin{tabular}{|c|c|c|c|c|c|}
\hline $\begin{array}{l}\text { Signaling pathway } \\
\text { (Cell line or } \\
\text { biological target) }\end{array}$ & $\begin{array}{l}\text { Monomer } \\
\left(\mathrm{IC}_{50} \mu \mathrm{M}\right)\end{array}$ & $\begin{array}{l}\text { Dimer } \\
\left(\mathrm{IC}_{50} \mu \mathrm{M}\right)\end{array}$ & $\begin{array}{l}\text { Trimer } \\
\left(\mathrm{IC}_{50} \mu \mathrm{M}\right)\end{array}$ & $\begin{array}{l}\text { Tetramer } \\
\left(\mathrm{EC} / \mathrm{IC}_{50}\right. \\
\mu \mathrm{M})\end{array}$ & References \\
\hline Apoptosis (SW480) & $\begin{array}{l}\text { resveratrol } \\
(22.1)\end{array}$ & $\begin{array}{l}\varepsilon \text {-viniferin } \\
(>100)\end{array}$ & $\begin{array}{l}\alpha \text {-viniferin } \\
(18.5)\end{array}$ & $\begin{array}{l}\text { vaticanol C } \\
\text { (3.6) } \\
\text { hopeaphenol } \\
(28.6)\end{array}$ & $\begin{array}{l}\text { (Ito et al. } \\
\underline{2003} \text { ) }\end{array}$ \\
\hline Apoptosis (HL60) & $\begin{array}{l}\text { resveratrol } \\
(13.1)\end{array}$ & $\begin{array}{l}\varepsilon \text {-viniferin } \\
(44.2)\end{array}$ & $\begin{array}{l}\alpha \text {-viniferin } \\
(5.2)\end{array}$ & $\begin{array}{l}\text { vaticanol C } \\
\text { (3.0) } \\
\text { hopeaphenol } \\
(21.3)\end{array}$ & \\
\hline $\begin{array}{l}\text { Chromosome } \\
\text { condensation (DNA } \\
\text { topoisomerase II) }\end{array}$ & $\begin{array}{l}\text { resveratrol } \\
(262)\end{array}$ & $\begin{array}{l}\text { balanocarpol } \\
\text { (47) }\end{array}$ & $\begin{array}{l}\alpha \text {-viniferin } \\
(27) \\
\alpha \text {-viniferin } 13-O \text { - } \\
\beta \text { - } \\
\text { glucopryranoside } \\
(4)\end{array}$ & $\begin{array}{l}\text { hemsleyanol } \\
\text { C (1) }\end{array}$ & $\begin{array}{l}\text { (Yamada et } \\
\underline{\text { al. 2006) }}\end{array}$ \\
\hline $\begin{array}{l}\text { Cholinergic } \\
\text { neurotransmission } \\
\text { (Cholinesterase) }\end{array}$ & $\begin{array}{l}\text { resveratrol } \\
(>5)\end{array}$ & NA & $\begin{array}{l}\alpha \text {-viniferin } \\
(2)\end{array}$ & $\begin{array}{l}\text { kobophenol } \\
\text { A } \\
(115.8)\end{array}$ & $\begin{array}{l}\text { (Pinho et al. } \\
\text { 2013; Sung } \\
\text { et al. 2002) }\end{array}$ \\
\hline $\begin{array}{l}\text { Drug resistance } \\
\text { (MRP1) }\end{array}$ & $\begin{array}{l}\text { resveratrol } \\
(\mathrm{NE})\end{array}$ & $\begin{array}{l}\varepsilon \text {-viniferin } \\
(8.9)\end{array}$ & $\begin{array}{l}\alpha \text {-viniferin } \\
(0.8)\end{array}$ & NA & $\begin{array}{l}\text { Bobrowska- } \\
\text { Hagerstrand } \\
\text { et al. 2006) }\end{array}$ \\
\hline $\begin{array}{l}\text { ER stress (F9 Herp- } \\
\text { null) }\end{array}$ & $\begin{array}{l}\text { resveratrol } \\
(\mathrm{NE})\end{array}$ & $\begin{array}{l}\varepsilon \text {-viniferin } \\
(\mathrm{NE})\end{array}$ & NA & $\begin{array}{l}\text { vaticanol B } \\
(\sim 5-10)\end{array}$ & $\begin{array}{l}\text { (Tabata et al. } \\
\text { 2007) }\end{array}$ \\
\hline $\begin{array}{l}\text { Gene transcription } \\
(\operatorname{PPAR} \alpha)\end{array}$ & $\begin{array}{l}\text { resveratrol } \\
\text { (5) }\end{array}$ & $\begin{array}{l}\varepsilon \text {-viniferin } \\
(\mathrm{NE})\end{array}$ & NA & $\begin{array}{l}\text { vaticanol C } \\
(2.5)\end{array}$ & $\begin{array}{l}\text { (Tsukamoto } \\
\text { et al. 2010) }\end{array}$ \\
\hline $\begin{array}{l}\text { Growth inhibition } \\
\text { (P-388) }\end{array}$ & NA & $\begin{array}{l}\text { balanocarpol } \\
(33.6)\end{array}$ & $\begin{array}{l}\alpha \text {-viniferin } \\
(25.8)\end{array}$ & $\begin{array}{l}\text { hopeaphenol } \\
\text { (5.7) }\end{array}$ & $\begin{array}{l}\text { (Sahidin et } \\
\text { al. 2005) }\end{array}$ \\
\hline $\begin{array}{l}\text { Growth inhibition } \\
\text { (MCF7) }\end{array}$ & $\begin{array}{l}\text { resveratrol } \\
(>70)\end{array}$ & $\begin{array}{l}\text { parviflorol } \\
(>30)\end{array}$ & $\begin{array}{l}\text { pauciflorol B } \\
(5.0)\end{array}$ & $\begin{array}{l}\text { vaticaffinol } \\
(9.6)\end{array}$ & $\begin{array}{l}\text { (Qiao et al. } \\
\underline{2013})\end{array}$ \\
\hline $\begin{array}{l}\text { Growth inhibition } \\
\text { (MDA-MB-231) }\end{array}$ & $\begin{array}{l}\text { resveratrol } \\
(>70)\end{array}$ & $\begin{array}{l}\text { parviflorol } \\
(>30)\end{array}$ & $\begin{array}{l}\text { pauciflorol B } \\
(17.7)\end{array}$ & $\begin{array}{l}\text { vaticaffinol } \\
(26.3)\end{array}$ & \\
\hline $\begin{array}{l}\text { Growth inhibition } \\
\text { (MCF7) }\end{array}$ & $\begin{array}{l}\text { resveratrol } \\
(50)\end{array}$ & $\begin{array}{l}\varepsilon \text {-viniferin } \\
(10)\end{array}$ & NA & NA & $\begin{array}{l}(\underline{\operatorname{Lim}} \text { et al. } \\
\underline{2012 \mathrm{a})}\end{array}$ \\
\hline $\begin{array}{l}\text { Growth and } \\
\text { survival (SK1) }\end{array}$ & $\begin{array}{l}\text { resveratrol } \\
(160)^{*}\end{array}$ & $\begin{array}{l}\varepsilon \text {-viniferin } \\
(90)^{*}\end{array}$ & NA & NA & \\
\hline
\end{tabular}

* values indicate inhibition constant $\left(\mathrm{K}_{\mathrm{i}}\right)$; NA, Not Available; NE, Not Effective; ER, Endoplasmic Reticulum; MRP1, Multidrug Resistance-Associated Protein 1; PPAR $\alpha$, Peroxisome Proliferator-Activated Receptor $\alpha$ 


\subsection{Pharmacokinetics and toxicity}

One of the main obstacles in translating the beneficial effects of resveratrol to the clinic is its poor pharmacokinetic profile. Various studies have documented the bioavailability of resveratrol in human and animals. Resveratrol is quickly metabolized in the body to sulphate and glucuronide conjugates within 30 minutes of intravenous administration; the half-lives of resveratrol and total resveratrol metabolite is 8-14 minutes and approximately 9 hours respectively (Baur and Sinclair 2006). Notably, resveratrol sulphate is actively taken up by cells and provides a reservoir of intracellular resveratrol. Peak plasma and local tissues concentration of resveratrol sulphate after oral dosing of $1 \mathrm{~g}$ daily is 30 and $640 \mu \mathrm{M}$ respectively (Patel et al. 2013). Resveratrol is delivered to cells as a sulphate conjugate that is further metabolized by the cells to regenerate resveratrol. Therefore, bioavailability of resveratrol and its route of administration/delivery system may not be a major concern.

Toxicity is an issue that requires consideration. This is especially true for resveratrol, which has to be administered at high dosage to achieve clinical response including anti-cancer effects. However, resveratrol does not appear to have any detrimental effects in rats at $300 \mathrm{mg} / \mathrm{kg}$. Toxicity in man is less well studied or documented due to multiple challenges associated with human clinical trials (Smoliga et al. 2012). Very recently, resveratrol administered to non-human primates was found to exhibit several health benefits as observed from rodent studies. However, an abnormal developmental effect was found in fetal pancreas, arguing against the use of resveratrol in pregnant woman (Roberts et al. 2014). Resveratrol might also interact with other dietary supplements or drugs as it inhibits human cytochrome P450 (CYP) enzymes (Baur and Sinclair 2006). $\alpha$-viniferin also inhibits 7 out of 9 human CYP isoforms that are involved in drug metabolism, indicating the potential for drug interactions ( effects of resveratrol and its oligomers should be thoroughly examined before they can be recommended for long-term use. 


\section{Sphingolipids}

Lipids (glycerolipids, sphingolipids and sterols) are ubiquitous biomolecules that are involved in the regulation of cellular homeostasis in health and disease. Bioactive sphingolipids play important roles in mammalian cell signaling (Hannun and Obeid 2008). The name of sphingolipids is derived from the mystical "sphinx", which suggests their enigmatic properties. For decades, sphingolipids have been considered as inert structural components of the cell membranes. Sphingolipids have come of age and have emerged as pleiotropic signaling molecules that regulate various cellular processes such as apoptosis (Hannun and Bell 1989). Sphingolipids also stabilize lipid microdomains (or "lipid rafts") where cell signaling is compartmentalized and facilitated by the biophysical functions of sphingolipids (Futerman and Hannun 2004). Certain molecular species of ceramide induce apoptosis (Obeid et al. 1993) whereas sphingosine-1-phosphate (S1P) promotes cell proliferation (Olivera and Spiegel 1993), prevents apoptosis (Cuvillier et al. 1996) and functions as a ligand for five G-protein coupled receptors (named $\mathrm{S}_{1-\mathrm{P}_{1-5}}$ ). Moreover, S1P signaling plays a major role in many human diseases including cancers (Pyne and Pyne 2010) and immune disorders (Pyne and Pyne 2011). Furthermore, the sphingolipid pathway has been successfully targeted by Fingolimod (FTY720), the first FDA-approved drug modulating the $\mathrm{S}_{1} \mathrm{P}_{1}$ receptor and now licensed as Gilenya ${ }^{\circledR}$ for the treatment of relapsing-remitting multiple sclerosis (Brinkmann et al. 2010). In recent years, compounds such as RPC1063 and ponesimod (ACT-128800) that selectively target the $\mathrm{S}_{1} \mathrm{P}_{1}$ receptor have entered clinical trials for the treatment of autoimmune diseases including multiple sclerosis, psoriasis and ulcerative colitis. Moreover, the S1P specific monoclonal antibody, Sonepcizumab ('S-one-P' cizumab) or LT1009 has been developed into two different formulations for clinical trials: (i)

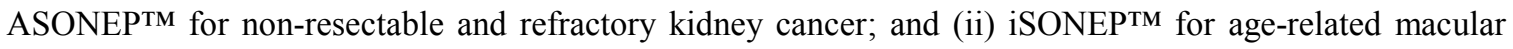
degeneration. These clinical evaluations highlight the therapeutic potential of modulating S1P signaling in chronic inflammatory diseases ( $\underline{\text { Schwalm et al. 2014) }}$.

\subsection{Sphingolipid Metabolism}

There are a multitude of lipids with distinct structures that are present in cells (Futerman and Hannun 2004). This structural diversity and complexity is the result of the availability of diverse substrates for lipidmetabolizing enzymes. With the advent of molecular cloning and biochemical analysis, the sphingolipid 
metabolic pathways have been elucidated. The neutral building block of all sphingolipids is ceramide that is either formed by de novo synthesis at the endoplasmic reticulum (ER) or activation of sphingomyelinases which function in the so-called 'salvage pathway'. In the ER, serine and pamitoyl coenzyme A is condensed by serine palmitoyl transferase (SPT) to form 3-ketosphinganine that is reduced to dihydrosphingosine followed by N-acylation to form dihydroceramide. In turn, dihydroceramide can be desaturated to form ceramide (Fig. 3). SPT has recently been shown to be negatively regulated by the Orm proteins that are encoded by the ORMDL genes in human (Breslow et al. 2010). Through genome wide association studies, $O R M D L 3$ gene has been implicated as a significant risk factor for childhood asthma, primary biliary cirrhosis, diabetes and Crohn's disease. These findings suggest that disruption of sphingolipid homeostasis could play a role in pathogenesis of these inflammatory diseases (Breslow et al. 2010). Sphingomyelinases catalyze the hydrolysis of sphingomyelin that is abundant in the cellular membrane to produce ceramide in the sphingosine salvage pathway. Sphingomyelinases are broadly categorized in neutral, acid or alkaline forms. Ionizing radiation activates acid sphingomyelinase to produce ceramide which promotes the induction of apoptosis (Haimovitz-Friedman et al. 1994), implicating a crucial role for this enzyme in mediating stress-induced apoptosis (Santana et al. 1996). Conversely, a cell permeable and non-competitive inhibitor of neutral sphingomyelinase (GW4869) blocks ceramide synthesis to rescue cell death in numerous cell types, such as cochlear hair cells (Chi et al. 2014), retinal pigment epithelial cells (Kucuksayan et al. 2014) and fibroblasts (Qin et al. 2012). At least four isoforms of neutral sphingomyelinase are expressed in mammalian cells, each with distinct biochemical properties, localizations and physiological roles (for a review, see Airola and Hannun 2013)). Alkaline sphingomyelinases are less well studied. These enzymes are expressed mainly in the intestines and could be implicated in various digestive tract diseases (Duan 2006). Together, these studies provide a strong rationale for therapeutic targeting of sphingomyelinases to modulate the level of ceramide in various diseases.

Ceramide can be deacylated (removal of the fatty acid side chain) through a reaction catalyzed by ceramidase. Conversely, sphingosine can be acylated by ceramide synthase to produce ceramide. Phosphorylation of sphingosine is catalyzed by sphingosine kinase (two isoforms termed SK1 and SK2) to produce S1P, which can be recycled to sphingosine by lipid phosphate phosphatases or S1P specific 
phosphatases. Alternatively, S1P is cleaved by S1P lyase to produce phosphoethanolamine and (E)-2hexadecenal and this represents the only exit point in the sphingolipid metabolic pathway (Fig. 3).

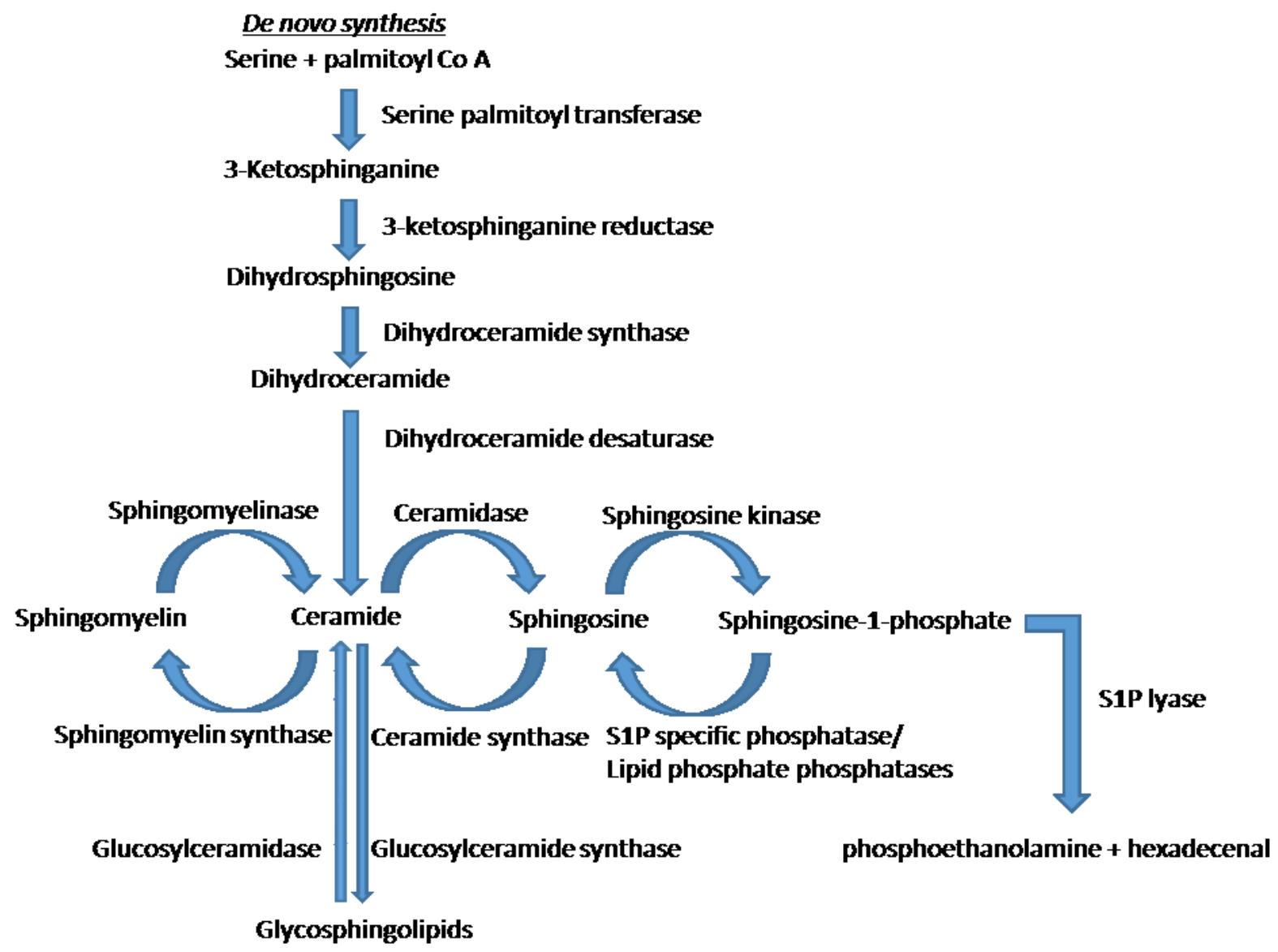

Figure 3. Sphingolipid metabolism. Degradation of sphingomyelin or de novo synthesis produces ceramide that is the precursor of sphingosine, sphingomyelin and glycosphingolipids. Sphingosine is phosphorylated by sphingosine kinase to form sphingosine-1-phosphate (S1P) which can be recycled back to sphingosine by enzymes like S1P specific phosphatases. S1P is irreversibly cleaved by S1P lyase to exit the sphingolipid metabolic pathway.

Understanding the metabolism of sphingolipids is essential to dissect the mechanisms of action for agents that perturb sphingolipid levels. In addition, these metabolic pathways are bi-directional and sphingolipid levels are tightly regulated in cells. For example, the apparent failure of a ceramide-inducing agent to promote apoptosis might be due to an active clearance of ceramide by ceramidase. Indeed, ceramidase 
inhibitors might be usefully exploited to reduce ceramide clearance and hence potentiate ceramidedependent apoptosis (Canals et al. 2011). In diseased states, one or more of these metabolic pathways might be deregulated resulting in over-production of a metabolite; for example, by over-expression of the anabolic enzymes or down-regulation of the catabolic enzymes. Indeed, S1P levels are increased by elevated expression of SK1 in multiple human cancers (Pyne and Pyne 2010). In addition, down-regulation of alkaline sphingomyelinase has been observed in human colon and liver cancers leading to reduction of ceramide level and attenuation of apoptosis (Cheng et al. 2007; Duan 2005). Therefore, the interconversion of these sphingolipid metabolites must be considered when assessing the cellular phenotype upon gene knockdown or treatment with pharmacological therapeutic agents.

\subsection{Biological activity of sphingolipids}

The sphingolipid 'rheostat' has been proposed as a model to explain the biological activity of ceramide, sphingosine and S1P in determining cell fate (Cuvillier et al. 1996). According to this concept, the balance of the ceramide, sphingosine and S1P levels defines whether cells undergo proliferation or apoptosis or senescence or differentiation The anti-apoptotic role of S1P has also been linked to the promotion of macroautophagy (simply termed as autophagy, a self-degradation process) (Lavieu et al. 2006). Autophagy maintains cellular homeostasis by regulating turnover of cellular components and plays important roles in determining cell fate (Green and Levine 2014). Autophagy can promote cell survival or cell death depending on which autophagy gene products are switched on (Codogno and Meijer 2005). Emerging evidence suggests that ceramide has a complex role in autophagy, promoting cell death in a contextdependent manner (Jiang and Ogretmen 2014). Ceramide also has diverse cellular targets, such as protein phosphatase 2A, p38, JNK, PKC, survivin and other proteins that regulate cell cycle and apoptosis (Morad and Cabot 2013). On the other hand, sphingosine was initially found to inhibit protein kinase C, exert antiproliferative effects and exhibit cell-type specific functions (Hannun and Bell 1989). Sphingosine also regulates nuclear lipid signaling as it has been shown to bind the nuclear receptor, Steroidogenic Factor-1, that mediates steroid biosynthesis, and primase that regulates synthesis of RNA primers (Simbulan et al. 1994; Urs et al. 2006). More recently, sphingosine has been found to activate Translesion DNA Polymerase to promote cell proliferation (Kamath-Loeb et al. 2014). Moreover, the cellular effects of sphingosine are 
cell-type and cell-context dependent. Notably, sphingosine can be converted to S1P by the action of SK1 or SK2 to stimulate cell proliferation. S1P functions both intracellularly (by binding to its target proteins) and extracellularly (through agonism of cell surface S1P-specific receptors). Moreover, the S1P signalling axis is implicated in many human diseases including inflammation and cancer (Dilshara et al. 2014; Kunkel et al. 2013; Pyne and Pyne 2010), providing opportunities for development of SK1 or SK2 inhibitors and S1P receptor agonists or antagonists as therapeutic agents.

\subsection{S1P signaling}

$\mathrm{S} 1 \mathrm{P}$ acts on extracellular receptors $\left(\mathrm{S}_{1} \mathrm{P}_{1-5}\right)$ to regulate diverse cellular responses, such as cell proliferation, migration, differentiation and immune cell trafficking. Each receptor is preferentially coupled to a subset of $\mathrm{G}$ proteins that regulate various effectors. The effects of S1P receptor-mediated signaling depend on the relative expression of S1P receptor sub-types. S1P also acts intracellularly to promote epigenetic regulation, calcium mobilization, mitogenesis, inflammation and apoptosis suppression. Hence, to dissect the effects of S1P on cells, both extracellular and intracellular actions have to be considered.

SK1 is activated in response to stimulation of many receptor types. This involves SK1 translocation to the plasma membrane where S1P is formed. S1P may then be transported actively across the lipid bilayer (Kim et al. 2009) to act as an autocrine signal ("inside-out" or sequential signaling (Takabe et al. 2008)). By contrast, integrative signaling can enhance the co-migratory effect of extracellular S1P with other growth factors acting via S1P receptors and receptor tyrosine kinases (Waters et al. 2006).

In the circulation, immune cell trafficking is regulated by a S1P gradient (high S1P concentration in blood and lymph, low S1P concentration in tissues) (Hla et al. 2008). The S1P transporter spinster homolog 2 (Spns2) is responsible for S1P export from lymphatic endothelial cells, which mediates lymphocyte egress (Fukuhara et al. 2012). In the plasma, S1P is carried by apolipoprotein M in a complex with high-density lipoprotein (HDL) (Christoffersen et al. 2011). Apolipoprotein M not only functions as a vehicle to carry and deliver its S1P to different tissues but to also stimulate S1P synthesis in the liver (Liu et al. 2014) and to induce insulin secretion (Kurano et al. 2014). 
Therapeutic targeting of S1P signaling has gained momentum with the recent resolution of the crystal structures of SK1 (Wang et al. 2013), S1P 1 (Hanson et al. 2012) and S1P lyase (Bourquin et al. 2010). Molecular interactions between inhibitors and SK1 can now be modeled accurately to elucidate the structure-activity relationship of these inhibitors (Baek et al. 2013). The structure also provides an avenue for the study of potential allosteric modulators of SK1 (Lim et al. 2012b; Lim et al. 2001a; Liu et al. 2013). SK2, a larger protein than SK1 and with differing biochemical properties and distribution, is less well characterized. Nevertheless, SK2 appears to play a contributory role in cancer and inflammatory diseases as evidenced by the therapeutic effects observed with SK2 inhibitors in vitro and in preclinical disease models (Lim et al. 2011b, Neubauer and Pitson 2013). Therefore, solving the atomic structure of SK2 would accelerate the development of specific SK2 inhibitors and advance our understanding of the role of SK2 in various diseases. Similarly, the crystal structure of $\mathrm{S}_{1} \mathrm{P}_{1}$ provides mechanistic insights into how this receptor can be effectively targeted. Interestingly, the N-terminus and extracellular loops of the receptor blocks ligand access; S1P appears to slide horizontally in the transmembrane region to enter the binding pocket (Hanson et al. 2012). Since the only approved S1P $\mathrm{P}_{1}$ modulator (FTY720) is not selective,

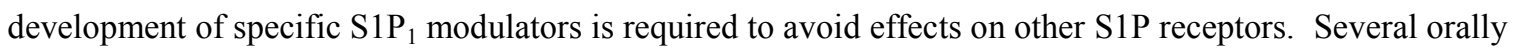
active S1P lyase inhibitors are also in preclinical development, offering new approaches for the treatment of autoimmune diseases like multiple sclerosis and rheumatoid arthritis (Bagdanoff et al. 2010; Weiler et al. 2014).

Targeting S1P production or removal may affect receptor-mediated actions of S1P (i.e. extracellular) but also its intracellular actions. For example, S1P has been found to play a role in the nucleus by binding to and inhibiting histone deacetylases (HDACs) (Hait et al. 2009). Phorbol ester can activate SK2 to increase S1P levels which bind to and inhibit HDAC1/2. This leads to up-regulation of cyclin-dependent kinase (CDK) inhibitor $p 21$ and the proto-oncogene c-fos. This suggests that intracellular S1P is an important epigenetic regulator (Hait et al. 2009). In addition, S1P binds TRAF2 in the cytoplasm and increases TRAF2-dependent polyubiquitination of receptor interacting protein 1 (RIP1). RIP1 is a scaffold protein for IKK-dependent regulation of the NF- $\mathrm{kB}$ pathway that regulates pro-inflammatory responses (Alvarez et al. 2010). Intracellular S1P also regulates mitochondrial assembly and respiration by binding to a mitochondrial protein, prohibitin 2 and promoting respiratory complex IV assembly (Strub et al. 2011). In 
addition, intracellular S1P can bind to and enhance $\beta$-site APP cleaving enzyme-1 (BACE1) activity to increase $\beta$-amyloid production, which contributes to the pathogenesis of Alzheimer's disease (Takasugi et al. 2011). More recently, S1P binding to cellular inhibitor of apoptosis 2 (cIAP2) has been shown to trigger interferon-regulatory factor 1 (IRF1) polyubiquitination that is essential for IL1-dependent expression of CXCL10 and CCL5 chemokines (Harikumar et al. 2014). Recently, FTY720 phosphate (the SK2 phosphorylated derivative of FTY720) was shown to inhibit HDACs in a fashion similar to S1P and to eliminate fear memories in mice, implicating a new role of S1P in memory formation (Hait et al. 2014). Together, these studies consolidate our understanding on S1P signaling in normal and pathological processes and reveal new therapeutic opportunities.

\section{Effects of resveratrol on sphingolipids in disease}

The prevalence of cancer, cardiovascular, neurodegenerative diseases and metabolic disorders increases with age. In this regard, the effects of resveratrol in slowing the progression of age-related diseases are well documented (Baur et al. 2012). Interestingly, sphingolipids, such as ceramide and dihydroceramide have been shown to modulate lifespan of yeast via autophagy and activation of AMPK signaling that is independent of sirtuin activation (Huang et al. 2014). Since resveratrol modulates sphingolipid levels, the beneficial effects of resveratrol such as anti-cancer, anti-inflammatory activities, cardio- and neuroprotective properties might be tightly linked with changes in sphingolipid signaling. The following section provides evidence for the role of sphingolipids in mediating the activities of resveratrol in multiple human diseases.

\subsection{Cancer and Inflammation}

Resveratrol alters sphingolipid levels through multiple mechanisms. Firstly, resveratrol increases ceramide to induce apoptosis in colon, breast and prostate cancer cells. Similarly, synthetic resveratrol analogues with minor side-chain modifications induce ceramide-dependent apoptosis (Minutolo et al. 2005). The effect of resveratrol is through increased de novo ceramide biosynthesis and is reversed by SPT inhibitors (Dolfini et al. 2007; Sala et al. 2003; Scarlatti et al. 2007; Scarlatti et al. 2003; Ulrich et al. 2007). However, ceramide levels increase 24-48 hours after resveratrol treatment (Scarlatti et al. 2003), which correlates 
with the onset of apoptosis (Delmas et al. 2003; Dimanche-Boitrel et al. 2005), and suggesting de novo changes in the expression of enzymes involved in ceramide metabolism. The mechanisms by which resveratrol and ceramide induce apoptosis in ovarian cancer cells are partially overlapped and involve a COX-2-dependent pathway (Lin et al. 2013). Resveratrol also increases dihydroceramide levels by reducing the activity of dihydroceramide synthases in gastric cancer cells (Shin et al. 2012). There is also increasing evidence that resveratrol can induce autophagy by modulating sphingolipid levels in cancer cells. In this regard, resveratrol increases dihydroceramide levels and induces autophagy that is possibly linked with inhibition of growth of HCG-27 gastric cancer cells ( $\underline{\text { Signorelli et al. 2009)}}$. In addition, resveratrol has been shown to induce autophagic cell death in human breast cancer ( Scarlatti et al. 2008), colorectal

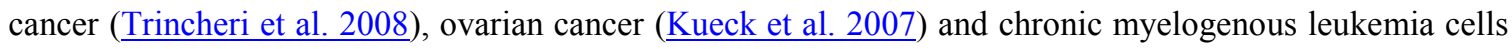
(Puissant et al. 2010). Therefore, resveratrol induced changes in ceramide, dihydroceramide and S1P levels appear linked with inhibition of proliferation, stimulation of autophagy and induction of cancer cell death.

Blockade of NF- $\mathrm{BB}$ signaling is one of the early events observed with resveratrol treatment. For example,

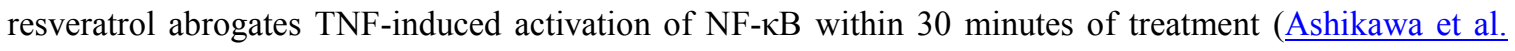
2002; Manna et al. 2000). Moreover, pre-treatment of endothelial cells with SGE (a red grape skin polyphenolic extract, containing resveratrol oligomers) reduces the responsiveness of these cells to S1Pinduced migration, ERK1/2 activation and platelet-activating factor synthesis (Barthomeuf et al. 2006). NF$\kappa \mathrm{B}$ is a proposed downstream effector of S1P (Alvarez et al. 2010). Therefore, the effects of SGE in blocking S1P-dependent angiogenesis might lie upstream of NF- $\kappa$ B . Indeed, Issuree and colleagues (2009) showed that resveratrol inhibits SK1-induced inflammatory response triggered by C5a (a chemoattractant cytokine). Resveratrol also inhibits activation of phospholipase D (PLD) which is an upstream activator of SK1 (Issuree et al. 2009). Dietary polyphenols including resveratrol also down-regulate SK1 expression and activity in prostate cancer cells (Brizuela et al. 2010). These studies suggest that resveratrol inhibits the ERK/PLD pathway which is upstream of SK1 activation. However, direct inhibition of purified SK1 activity by resveratrol has been observed and treatment of MCF-7 breast cancer cells with resveratrol induces down-regulation of SK1 expression (Lim et al. 2012a). The inhibition of SK1 activity by resveratrol is likely to disrupt the sphingolipid rheostat and to increase ceramide levels. This might account for the ability of resveratrol to induce apoptosis of MCF-7 breast cancer cells (Lim et al. 2012a). Moreover, 
balanocarpol and its isomer, ampelopsin A also inhibit SK1 activity and down-regulate SK1 expression, which induces apoptosis in MCF-7 breast cancer cells (Lim et al. 2012a). Interestingly, resveratrol upregulates ceramide synthases and down-regulates SK1 expression in myeloid leukemia cells (Cakir et al. 2011). Resveratrol also reduces activity of SK1 in a rat model of ulcerative colitis and ablates severity of oxazolone-induced inflammation (Abdin 2013). Perturbation of the sphingolipid rheostat by resveratrol and oligomers might therefore be partly responsible for the anti-inflammatory and anti-cancer activities of these compounds.

\subsection{Cardiovascular disease}

Circulating S1P is bound to HDL $(\sim 55 \%)$, albumin $(\sim 35 \%)$ and LDL/VLDL $(<10 \%)$ and is derived from vascular endothelial and red blood cells in a range between 200-900 nM (Poti et al. 2014). At this concentration, S1P dissociates from its carrier proteins to exert cardiovascular and atheroprotective effects by binding to S1P receptors. Indeed, circulating S1P or activation of intracellular SK1 confers protection against myocardial infarction and acute ischemia/reperfusion injury (Karliner 2013). Even though the overall effect of S1P on the heart and vasculature appears protective after injury, several studies report conflicting results due to the pro-fibrotic, heart muscle thickening and vasoconstrictive properties of S1P

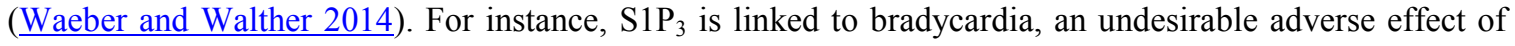
FTY720 phosphate (Means and Brown 2009). Therefore, compounds selectively targeting the $\mathrm{S}_{1} \mathrm{P}_{1}$ receptor might be better suited for the treatment of myocardial infarction (Waeber and Walther 2014). The consensus is that further investigations employing larger animal models, selective pharmacological tools and more epidemiological studies are required to improve our understanding of the role of S1P and thereby enable development of new therapeutic agents for treatment of cardiovascular disease.

Despite favorable outcomes observed for resveratrol and other polyphenolic compounds in many in vitro and in vivo models of cardiovascular disease, the evidence for cardioprotection is not unequivocal in

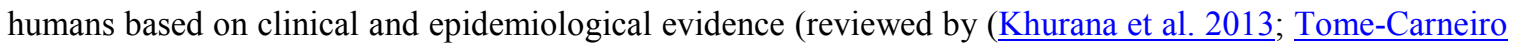
et al. 2013). For example, even though resveratrol appears beneficial against myocardial infarction in animal models, several recent large-scale analyses have argued against a protective effect of resveratrol in humans. In addition, the effect of resveratrol on lipoprotein metabolism is not significant in a meta-analysis 
of seven randomized controlled trials ( $\underline{\text { Sahebkar 2013) }}$. Similarly, Semba and colleagues did not find an association between resveratrol and any health benefits after following 783 individuals for 9 years (Semba et al. 2014). More long-term controlled trials will assess the use of resveratrol as a dietary supplement for prevention or as a drug for treatment of cardiovascular diseases.

Since resveratrol and its oligomers modulate sphingolipid metabolism and increases pro-apoptotic ceramide levels, future studies should explore whether this effect is cell-type specific. For example, due to constant exposure to UV irradiation, keratinocytes have evolved a protective mechanism to convert ceramide to S1P by activating ceramidase and SK1 (Uchida 2014). Intriguingly, resveratrol increases ceramide levels (via activation of SPT) and S1P formation (by increasing SK1 mRNA expression), which leads to increased antimicrobial defense in human skin cells (Park et al. 2013). Therefore, possibly through this metabolic conversion of ceramide to S1P, resveratrol may have a protective role in some cell types. Low concentration of resveratrol $(<50 \mu \mathrm{M})$ increases sphingosine, ceramide and S1P levels in human skin cells but high concentration of resveratrol reduces cell viability (Park et al. 2013). This is consistent with the effect of resveratrol in cancer cells where high concentration $(>50 \mu \mathrm{M})$ of resveratrol induce apoptosis possibly involving inhibition of SK1 activity and down-regulation of SK1 expression (Lim et al. 2012a). Thus, the effects of resveratrol on SK activity and sphingolipid metabolism appear concentration dependent and this will define the effect of resveratrol on cellular outcome.

Therefore, the use of resveratrol to modulate sphingolipid levels and signaling in cardiovascular disease requires careful consideration. Clearly, the ability of resveratrol to increase ceramide levels either by activating SPT or by inhibiting SK1 activity might dictate a pro-apoptotic effect which would be deleterious. Second, the multifaceted roles of S1P in the cardiovascular system make it difficult to harness the beneficial effects of reducing S1P levels while avoiding unwanted side-effects. For example, inhibiting SK1 activity with resveratrol might reduce cardioprotection afforded by S1P associated with HDL and S1P-dependent activation of pro-survival signaling such as PI3K/Akt and MAPK pathways. However, S1P can reduce heart rate $\left(\mathrm{S}_{1} \mathrm{P}_{3}\right)$ and constrict coronary arteries $\left(\mathrm{S}_{1} \mathrm{P}_{2}\right)($ Waeber and Walther 2014) $)$ and these effects would be potentially alleviated by inhibiting SK1 activity/expression with resveratrol. Indeed, resveratrol has been shown to be effective in ameliorating hypertension, ischemic heart disease and 
cardiomyopathy in animal studies (Raj et al. 2014). A recent study has shown that resveratrol is effective in reducing arterial wall inflammation and stiffening (hallmarks of vascular aging) in rhesus monkeys fed with high fat diet, possibly through activation of the Nrf2 anti-oxidant pathway (Mattison et al. 2014). Resveratrol also exhibits anti-oxidant and anti-inflammatory properties due to modulation of other signaling pathways that might impact more significantly on cardioprotection than the modulation of S1P signaling. These include activation of AMPK, SIRT1 and NO signaling as well as inhibition of proinflammatory cytokine signaling such as the NF-kB pathway (Raj et al. 2014). Therefore, further investigations are needed to examine the effect of resveratrol on sphingolipid levels in cardiovascular disease models. Investigation of the activity of resveratrol oligomers which might be "fine-tuned" in specificity of action is also worthwhile, particularly given their ability to inhibit SK1 activity. Long-term studies are also needed to assess the side effects and toxicity of these compounds.

\subsection{Neurodegenerative disease}

Altered sphingolipids metabolism is linked to multiple neurodegenerative diseases, such as Alzheimer's disease, Niemann Pick disease, amyotrophic lateral sclerosis, Parkinson and AIDS dementia (Mielke and Lyketsos 2010). The strongest evidence that modulation of sphingolipids by resveratrol might impact disease progression is in Alzheimer's disease. Alzheimer's disease is known to affect the elderly and is responsible for memory loss as a result of dementia. Central to the pathogenesis of Alzheimer's disease is BACE1 (also referred to as $\beta$-secretase), which is an enzyme responsible for the formation of neurototoxic $\beta$-amyloid and therefore, is a therapeutic target (Yan and Vassar 2014). S1P produced by SK2 has been found to be neurotoxic in S1P-lyase deficient mice (Hagen et al. 2011). SK2, located at the ER induces apoptosis by generating intracellular S1P or phosphorylating sphingoid-based substrates (Don et al. 2007; Maceyka et al. 2005). Moreover, knockdown of SK2 by siRNA or inhibition of SK2 activity with ABC294640 (a specific SK2 inhibitor, (French et al. 2010)) reduces $\beta$-amyloid production in N2a neuroblastoma cells, indicating that SK2-derived S1P activates BACE1 to increase $\beta$-amyloid level in mouse neurons (Takasugi et al. 2011). Therefore, inhibition of SK2 activity is predicted to have therapeutic value in reducing formation of $\beta$-amyloid. Inhibition of SK1 activity by resveratrol is likely to be counteracted by the fact that ceramide (which is increased by resveratrol) which might accumulate also 
increases $\beta$-amyloid levels (by increasing BACE1 stability) (Puglielli et al. 2003) and induces oxidative stress in neurons (Cutler et al. 2004). Interestingly, other lipids (e.g. neutral glycosphingolipids, anionic glycerolipids and sterols) have also been shown to stimulate BACE1 activity in a reconstituted proteoliposome system (Kalvodova et al. 2005). Moreover, an increased ceramide/S1P ratio favors apoptosis that might result in further neurodegeneration. Indeed, ceramide levels are high in Alzheimer's patient brain region that exhibit $\beta$-amyloid accumulation (Cutler et al. 2004). In addition, serum ceramide is also associated with increased risk of developing Alzheimer's disease in woman (Mielke et al. 2012). Moreover, down-regulation of SK1 or up-regulation of S1P lyase (both of which would likely result in reduced S1P level) expression are found in Alzheimer's patient brain tissue, suggesting that high ceramide/S1P ratio in the brain is neurotoxic (Ceccom et al. 2014; Couttas et al. 2014). Therefore, SK inhibitors (e.g. 2-(p-hydroxyanilino)-4-(p-chlorophenyl)thiazole, abbreviated as SKi) that inhibit both SK1 and SK2 activity would appear counterproductive (Lim et al. 2011b; Loveridge et al. 2010; Mielke and Lyketsos 2010). In addition, SKi has been found to increase dihydroceramide levels, possibly by inhibiting dihydroceramide desaturase (Cingolani et al. 2014; Loveridge et al. 2010). Dihydroceramide might also be linked to autophagy and ER stress, which mediates G0/G1 cell cycle arrest and suppresses cell proliferation (Gagliostro et al. 2012). In addition, defects in autophagy-related pathways are implicated in neurodegeneration (Nixon 2013). Substantial evidence has now demonstrated that sphingolipids regulate both autophagy and apoptotic pathways to determine cell survival (Li et al. 2014).

In Alzheimer's disease, resveratrol ameliorates various pathological features associated with $\beta$-amyloid and Tau protein misfolding, inflammation, cell metabolism, telomere shortening, mitochondria dysfunction and oxidative stress (Granzotto and Zatta 2014; Vingtdeux et al. 2008). A beneficial effect has been demonstrated lately for resveratrol supplementation in elderly patients who exhibit better memory performance associated with improved glucose metabolism and hippocampal functional connectivity (Izeddin 2014). Other polyphenols have been shown to penetrate the brain and exhibit anti-amyloidogenic activity that improves cognitive function in a mouse model of Alzheimer's disease (Wang et al. 2014). Indeed, it would be interesting to investigate the effect of resveratrol oligomers found in the red grape skin polyphenolic extract, SGE (Baechler et al. 2014). Thus far, several resveratrol oligomers are known to inhibit cholinesterase (Table 1) and suppress $\beta$-amyloid formation (Richard et al. 2011a), which might 
therefore benefit Alzheimer's patients. For example, $\varepsilon$-viniferin glucoside (a resveratrol dimer), has been shown to reduce $\beta$-amyloid aggregation and toxicity in vitro (Richard et al. 2011b). No formal assessment has been made in relation to changes in sphingolipid levels in neurons after treatment with resveratrol. Nevertheless, neuroprotection has been consistently observed at $<50 \mu \mathrm{M}$ of resveratrol, which is lower than the concentration required to inhibit SK1 activity $\left(\mathrm{K}_{\mathrm{i}}=160 \pm 40 \mu \mathrm{M}\right)$ and to induce apoptosis (Capiralla et al. 2012; Chen et al. 2005; Feng et al. 2013; Lim et al. 2012a; Marambaud et al. 2005; Wang et al. 2014). Therefore, low micromolar concentrations of resveratrol might mediate protection via a mechanism that does not involve changes in sphingolipid levels. A recent study has demonstrated that the resveratrol sulfate metabolites could effectively be taken up by cells and converted back to resveratrol in vivo (Patel et al. 2013). Thus, caution is needed because resveratrol might be actively taken up by neurons, which could result in higher intracellular than plasma concentration.

\subsection{Metabolic disease}

Ceramide has been implicated in the pathogenesis of metabolic diseases; for instance, by promoting insulin resistance, lipotoxicity and cell death (Russo et al. 2013). Significant changes in sphingolipid levels and upregulation of ceramide-producing enzymes have been observed in obese rodents, which are accompanied by activation of pro-inflammatory cytokine signaling ( receptor TLR4-mediated signaling leads to the activation of NF- $\mathrm{KB}$ and up-regulation of genes involved in the generation of ceramide and insulin resistance. In addition, ceramide inhibits pro-survival Akt signaling to induce cell death and suppress insulin sensitivity (Holland et al. 2011a; Maceyka et al. 2012). By contrast, pro-survival S1P stimulated by adiponectin (a hormone with anti-inflammatory function) activates AMPK (in a S1P receptor-dependent manner), which is required for mitochondrial biogenesis ( al. 2011b; Maceyka et al. 2012). Therefore, reducing the ceramide/S1P ratio is an attractive therapeutic goal for the management of diabetes.

Resveratrol has been shown to improve insulin sensitivity and protect against metabolic disease in mice fed with high-fat diet. This is associated with activation of AMPK/SIRT1/PGC-1 $\alpha$ pathway (Baur et al. 2006). Moreover, resveratrol might exhibit anti-obesity action by reducing the body weight and abdominal fat of experimental mice (Baek et al. 2014). However, translation of these beneficial effects to the clinic has been 
difficult. For example, there is a lack of physiological responses and no gene expression changes of metabolic and inflammatory biomarkers in obese man taking a high dose of resveratrol. Indeed, a recent review on all available clinical trials or interventions of obesity and Type II diabetes has found no significant benefits associated with resveratrol consumption (Timmers et al. 2013). Of note, clinical trials measuring health benefits might be difficult to design, which requires careful selection of patients, considering their health status, underlying morbidity, age, gender and sex. In addition, improved health and lifespan extension has been observed only in mice having high-fat diet but not in lean mice, suggesting that resveratrol might have a beneficial effect on patients with severe metabolic derangement. More controlled clinical studies are needed to investigate the therapeutic potential of resveratrol in metabolic diseases and its effects on sphingolipid metabolism.

\section{Summary and future direction}

The role of sphingolipids in the pathogenesis of human disease is widely recognized. During the past few years, more information regarding the therapeutic potential of resveratrol has also accumulated. Importantly, resveratrol can oligomerize into larger molecules with better potency than resveratrol and in some cases, better selectivity. More work is needed to investigate the in vivo activity of resveratrol oligomers and to assess their therapeutic efficacy and toxicity. We consider that changes in sphingolipid metabolism in response to resveratrol and related oligomers are likely to be beneficial in the treatment of cancer patients and, more speculatively, in cardiovascular disease patients. However, changes in sphingolipid metabolism in response to resveratrol in metabolic disorders and neurodegenerative diseases are contraindicated and likely deleterious. This conclusion is based on findings that the effects of resveratrol on sphingolipid metabolism and disease progression are concentration-dependent. At low micromolar concentrations of resveratrol, which exhibit cardioprotective and neuroprotective properties, there is minimal perturbation of sphingolipid metabolism (excluding cellular uptake and increased local concentration). However, at high concentration $(>50 \mu \mathrm{M})$, resveratrol increases pro-apoptotic ceramide and reduces pro-survival S1P levels, which suppresses cell growth and induces apoptosis. Therefore, a better understanding of the long-term effects of resveratrol (and its oligomers) on S1P- and ceramide-dependent 
modulation of disease progression is required. Nevertheless, the potential of the resveratrol/sphingolipid

partnership might offer new avenues for the treatment of cancer.

\section{References}

Abdin AA (2013) Targeting sphingosine kinase 1 (SphK1) and apoptosis by colon-specific delivery formula of resveratrol in treatment of experimental ulcerative colitis in rats. Eur J Pharmacol $718(1-3): 145-53$

Airola MV, Hannun YA (2013) Sphingolipid metabolism and neutral sphingomyelinases. Handb Exp Pharmacol(215):57-76

Alvarez SE, Harikumar KB, Hait NC, et al. (2010) Sphingosine-1-phosphate is a missing cofactor for the E3 ubiquitin ligase TRAF2. Nature 465(7301):1084-8

Ashikawa K, Majumdar S, Banerjee S, Bharti AC, Shishodia S, Aggarwal BB (2002) Piceatannol inhibits TNF-induced NF-kappaB activation and NF-kappaB-mediated gene expression through suppression of IkappaBalpha kinase and p65 phosphorylation. J Immunol 169(11):6490-7

Baechler SA, Schroeter A, Dicker M, Steinberg P, Marko D (2014) Topoisomerase II-targeting properties of a grapevine-shoot extract and resveratrol oligomers. J Agric Food Chem

Baek DJ, MacRitchie N, Anthony NG, et al. (2013) Structure-activity relationships and molecular modeling of sphingosine kinase inhibitors. J Med Chem 56(22):9310-27

Baek SH, Chung HJ, Lee HK, et al. (2014) Treatment of obesity with the resveratrol-enriched rice DJ-526. Sci Rep 4:3879

Bagdanoff JT, Donoviel MS, Nouraldeen A, et al. (2010) Inhibition of sphingosine 1-phosphate lyase for the treatment of rheumatoid arthritis: discovery of $(E)-1-(4-((1 R, 2 S, 3 R)-1,2,3,4-$ tetrahydroxybutyl)-1H-imidazol-2-yl)ethanone oxime (LX2931) and (1R,2S,3R)-1-(2-(isoxazol-3yl)-1H-imidazol-4-yl)butane-1,2,3,4-tetraol (LX2932). J Med Chem 53(24):8650-62

Barjot C, Tournaire M, Castagnino C, Vigor C, Vercauteren J, Rossi JF (2007) Evaluation of antitumor effects of two vine stalk oligomers of resveratrol on a panel of lymphoid and myeloid cell lines: comparison with resveratrol. Life Sci 81(23-24):1565-74

Barthomeuf C, Lamy S, Blanchette M, Boivin D, Gingras D, Beliveau R (2006) Inhibition of sphingosine1-phosphate- and vascular endothelial growth factor-induced endothelial cell chemotaxis by red grape skin polyphenols correlates with a decrease in early platelet-activating factor synthesis. Free Radic Biol Med 40(4):581-90

Baur JA, Pearson KJ, Price NL, et al. (2006) Resveratrol improves health and survival of mice on a highcalorie diet. Nature 444(7117):337-42

Baur JA, Sinclair DA (2006) Therapeutic potential of resveratrol: the in vivo evidence. Nat Rev Drug Discov 5(6):493-506

Baur JA, Ungvari Z, Minor RK, Le Couteur DG, de Cabo R (2012) Are sirtuins viable targets for improving healthspan and lifespan? Nat Rev Drug Discov 11(6):443-61

Bobrowska-Hagerstrand M, Lillas M, Mrowczynska L, et al. (2006) Resveratrol oligomers are potent MRP1 transport inhibitors. Anticancer Res 26(3A):2081-4

Borra MT, Smith BC, Denu JM (2005) Mechanism of human SIRT1 activation by resveratrol. J Biol Chem 280(17):17187-95

Bourquin F, Riezman H, Capitani G, Grutter MG (2010) Structure and function of sphingosine-1-phosphate lyase, a key enzyme of sphingolipid metabolism. Structure 18(8):1054-65

Breslow DK, Collins SR, Bodenmiller B, et al. (2010) Orm family proteins mediate sphingolipid homeostasis. Nature 463(7284):1048-53

Brinkmann V, Billich A, Baumruker T, et al. (2010) Fingolimod (FTY720): discovery and development of an oral drug to treat multiple sclerosis. Nat Rev Drug Discov 9(11):883-97

Brizuela L, Dayon A, Doumerc N, et al. (2010) The sphingosine kinase-1 survival pathway is a molecular target for the tumor-suppressive tea and wine polyphenols in prostate cancer. FASEB J 24(10):3882-94

Burns J, Yokota T, Ashihara H, Lean ME, Crozier A (2002) Plant foods and herbal sources of resveratrol. J Agric Food Chem 50(11):3337-40 
Buryanovskyy L, Fu Y, Boyd M, et al. (2004) Crystal structure of quinone reductase 2 in complex with resveratrol. Biochemistry 43(36):11417-26

Cakir Z, Saydam G, Sahin F, Baran Y (2011) The roles of bioactive sphingolipids in resveratrol-induced apoptosis in HL60: acute myeloid leukemia cells. J Cancer Res Clin Oncol 137(2):279-86

Canals D, Perry DM, Jenkins RW, Hannun YA (2011) Drug targeting of sphingolipid metabolism: sphingomyelinases and ceramidases. Br J Pharmacol 163(4):694-712

Canto C, Auwerx J (2012) Targeting sirtuin 1 to improve metabolism: all you need is NAD(+)? Pharmacol Rev 64(1):166-87

Capiralla H, Vingtdeux V, Zhao H, et al. (2012) Resveratrol mitigates lipopolysaccharide- and Abetamediated microglial inflammation by inhibiting the TLR4/NF-kappaB/STAT signaling cascade. J Neurochem 120(3):461-72

Ceccom J, Loukh N, Lauwers-Cances V, et al. (2014) Reduced sphingosine kinase-1 and enhanced sphingosine 1-phosphate lyase expression demonstrate deregulated sphingosine 1-phosphate signaling in Alzheimer's disease. Acta Neuropathol Commun 2(1):12

Chen J, Zhou Y, Mueller-Steiner S, et al. (2005) SIRT1 protects against microglia-dependent amyloid-beta toxicity through inhibiting NF-kappaB signaling. J Biol Chem 280(48):40364-74

Cheng Y, Wu J, Hertervig E, et al. (2007) Identification of aberrant forms of alkaline sphingomyelinase (NPP7) associated with human liver tumorigenesis. Br J Cancer 97(10):1441-8

Chi LN, Tabuchi K, Nakamagoe M, Nakayama M, Nishimura B, Hara A (2014) Ceramide/sphingomyelin cycle involvement in gentamicin-induced cochlear hair cell death. Arch Toxicol

Choi J, Chen J, Schreiber SL, Clardy J (1996) Structure of the FKBP12-rapamycin complex interacting with the binding domain of human FRAP. Science 273(5272):239-42

Christoffersen C, Obinata H, Kumaraswamy SB, et al. (2011) Endothelium-protective sphingosine-1phosphate provided by HDL-associated apolipoprotein M. Proc Natl Acad Sci U S A 108(23):9613-8

Chung EY, Kim BH, Lee MK, et al. (2003) Anti-inflammatory effect of the oligomeric stilbene alphaViniferin and its mode of the action through inhibition of cyclooxygenase-2 and inducible nitric oxide synthase. Planta Med 69(8):710-4

Chung EY, Roh E, Kwak JA, et al. (2010) alpha-Viniferin suppresses the signal transducer and activation of transcription-1 (STAT-1)-inducible inflammatory genes in interferon-gamma-stimulated macrophages. J Pharmacol Sci 112(4):405-14

Cingolani F, Casasampere M, Sanllehi P, Casas J, Bujons J, Fabrias G (2014) Inhibition of dihydroceramide desaturase activity by the sphingosine kinase inhibitor SKI II. J Lipid Res

Codogno P, Meijer AJ (2005) Autophagy and signaling: their role in cell survival and cell death. Cell Death Differ 12 Suppl 2:1509-18

Coggon P, Janes NF, King FE, et al. (1965) Hopeaphenol, an extractive of the heartwood of Hopea odorata and Balanocarpus heimii. J Chem Soc:406-9

Coggon P, Mcphail AT, Wallwork SC (1966) The structure of hopeaphenol. Chem Commun (London)(13):439-40

Couttas TA, Kain N, Daniels B, et al. (2014) Loss of the neuroprotective factor sphingosine 1-phosphate early in Alzheimer's disease pathogenesis. Acta Neuropathol Commun 2(1):9

Cutler RG, Kelly J, Storie K, et al. (2004) Involvement of oxidative stress-induced abnormalities in ceramide and cholesterol metabolism in brain aging and Alzheimer's disease. Proc Natl Acad Sci U S A 101(7):2070-5

Cuvillier O, Pirianov G, Kleuser B, et al. (1996) Suppression of ceramide-mediated programmed cell death by sphingosine-1-phosphate. Nature 381(6585):800-3

Dai JR, Hallock YF, Cardellina JH, 2nd, Boyd MR (1998) HIV-inhibitory and cytotoxic oligostilbenes from the leaves of Hopea malibato. J Nat Prod 61(3):351-3

Dayanandan S, Ashton PS, Williams SM, Primack RB (1999) Phylogeny of the tropical tree family Dipterocarpaceae based on nucleotide sequences of the chloroplast RBCL gene. Am J Bot 86(8):1182-90

Delmas D, Rebe C, Lacour S, et al. (2003) Resveratrol-induced apoptosis is associated with Fas redistribution in the rafts and the formation of a death-inducing signaling complex in colon cancer cells. J Biol Chem 278(42):41482-90 
Dilshara MG, Lee KT, Kim HJ, et al. (2014) Anti-inflammatory mechanism of alpha-viniferin regulates lipopolysaccharide-induced release of proinflammatory mediators in BV2 microglial cells. Cell Immunol 290(1):21-29

Dimanche-Boitrel MT, Meurette O, Rebillard A, Lacour S (2005) Role of early plasma membrane events in chemotherapy-induced cell death. Drug Resist Updat 8(1-2):5-14

Dolfini E, Roncoroni L, Dogliotti E, et al. (2007) Resveratrol impairs the formation of MDA-MB-231 multicellular tumor spheroids concomitant with ceramide accumulation. Cancer Lett 249(2):143-7

Don AS, Martinez-Lamenca C, Webb WR, Proia RL, Roberts E, Rosen H (2007) Essential requirement for sphingosine kinase 2 in a sphingolipid apoptosis pathway activated by FTY720 analogues. J Biol Chem 282(21):15833-42

Duan RD (2005) Anticancer compounds and sphingolipid metabolism in the colon. In Vivo 19(1):293-300

Duan RD (2006) Alkaline sphingomyelinase: an old enzyme with novel implications. Biochim Biophys Acta 1761(3):281-91

Feng X, Liang N, Zhu D, et al. (2013) Resveratrol inhibits beta-amyloid-induced neuronal apoptosis through regulation of SIRT1-ROCK1 signaling pathway. PLoS One 8(3):e59888

Fischbach MA, Clardy J (2007) One pathway, many products. Nat Chem Biol 3(7):353-5

Fremont L (2000) Biological effects of resveratrol. Life Sci 66(8):663-73

French KJ, Zhuang Y, Maines LW, et al. (2010) Pharmacology and antitumor activity of ABC294640, a selective inhibitor of sphingosine kinase-2. J Pharmacol Exp Ther 333(1):129-39

Fukuhara S, Simmons S, Kawamura S, et al. (2012) The sphingosine-1-phosphate transporter Spns2 expressed on endothelial cells regulates lymphocyte trafficking in mice. J Clin Invest 122(4):141626

Futerman AH, Hannun YA (2004) The complex life of simple sphingolipids. EMBO Rep 5(8):777-82

Gagliostro V, Casas J, Caretti A, et al. (2012) Dihydroceramide delays cell cycle G1/S transition via activation of ER stress and induction of autophagy. Int J Biochem Cell Biol 44(12):2135-43

Gledhill JR, Montgomery MG, Leslie AG, Walker JE (2007) Mechanism of inhibition of bovine F1ATPase by resveratrol and related polyphenols. Proc Natl Acad Sci U S A 104(34):13632-7

Gonzalez-Sarrias A, Gromek S, Niesen D, Seeram NP, Henry GE (2011) Resveratrol oligomers isolated from Carex species inhibit growth of human colon tumorigenic cells mediated by cell cycle arrest. J Agric Food Chem 59(16):8632-8

Granzotto A, Zatta P (2014) Resveratrol and Alzheimer's disease: message in a bottle on red wine and cognition. Front Aging Neurosci 6:95

Green DR, Levine B (2014) To be or not to be? How selective autophagy and cell death govern cell fate. Cell 157(1):65-75

Guebailia HA, Chira K, Richard T, et al. (2006) Hopeaphenol: the first resveratrol tetramer in wines from North Africa. J Agric Food Chem 54(25):9559-64

Gupta SC, Tyagi AK, Deshmukh-Taskar P, Hinojosa M, Prasad S, Aggarwal BB (2014) Downregulation of tumor necrosis factor and other proinflammatory biomarkers by polyphenols. Arch Biochem Biophys

Hagen N, Hans M, Hartmann D, Swandulla D, van Echten-Deckert G (2011) Sphingosine-1-phosphate links glycosphingolipid metabolism to neurodegeneration via a calpain-mediated mechanism. Cell Death Differ 18(8):1356-65

Haimovitz-Friedman A, Kan CC, Ehleiter D, et al. (1994) Ionizing radiation acts on cellular membranes to generate ceramide and initiate apoptosis. J Exp Med 180(2):525-35

Hait NC, Allegood J, Maceyka M, et al. (2009) Regulation of histone acetylation in the nucleus by sphingosine-1-phosphate. Science 325(5945):1254-7

Hait NC, Wise LE, Allegood JC, et al. (2014) Active, phosphorylated fingolimod inhibits histone deacetylases and facilitates fear extinction memory. Nat Neurosci 17(7):971-80

Hannun YA, Bell RM (1989) Functions of sphingolipids and sphingolipid breakdown products in cellular regulation. Science 243(4890):500-7

Hannun YA, Obeid LM (2008) Principles of bioactive lipid signalling: lessons from sphingolipids. Nat Rev Mol Cell Biol 9(2):139-50

Hanson MA, Roth CB, Jo E, et al. (2012) Crystal structure of a lipid G protein-coupled receptor. Science 335(6070):851-5 
Harikumar KB, Yester JW, Surace MJ, et al. (2014) K63-linked polyubiquitination of transcription factor IRF1 is essential for IL-1-induced production of chemokines CXCL10 and CCL5. Nat Immunol $15(3): 231-8$

Hla T, Venkataraman K, Michaud J (2008) The vascular S1P gradient-cellular sources and biological significance. Biochim Biophys Acta 1781(9):477-82

Holland WL, Bikman BT, Wang LP, et al. (2011a) Lipid-induced insulin resistance mediated by the proinflammatory receptor TLR4 requires saturated fatty acid-induced ceramide biosynthesis in mice. J Clin Invest 121(5):1858-70

Holland WL, Miller RA, Wang ZV, et al. (2011b) Receptor-mediated activation of ceramidase activity initiates the pleiotropic actions of adiponectin. Nat Med 17(1):55-63

Howitz KT, Bitterman KJ, Cohen HY, et al. (2003) Small molecule activators of sirtuins extend Saccharomyces cerevisiae lifespan. Nature 425(6954):191-6

Howitz KT, Sinclair DA (2008) Xenohormesis: sensing the chemical cues of other species. Cell 133(3):387-91

Huang X, Withers BR, Dickson RC (2014) Sphingolipids and lifespan regulation. Biochim Biophys Acta 1841(5):657-64

Hubbard BP, Gomes AP, Dai H, et al. (2013) Evidence for a common mechanism of SIRT1 regulation by allosteric activators. Science 339(6124):1216-9

Ingolfsson HI, Thakur P, Herold KF, et al. (2014) Phytochemicals perturb membranes and promiscuously alter protein function. ACS Chem Biol

Issuree PD, Pushparaj PN, Pervaiz S, Melendez AJ (2009) Resveratrol attenuates C5a-induced inflammatory responses in vitro and in vivo by inhibiting phospholipase $\mathrm{D}$ and sphingosine kinase activities. FASEB J 23(8):2412-24

Ito T, Akao Y, Tanaka T, Iinuma M, Nozawa Y (2002) Vaticanol C, a novel resveratrol tetramer, inhibits cell growth through induction of apoptosis in colon cancer cell lines. Biol Pharm Bull 25(1):147-8

Ito T, Akao Y, Yi H, et al. (2003) Antitumor effect of resveratrol oligomers against human cancer cell lines and the molecular mechanism of apoptosis induced by vaticanol C. Carcinogenesis 24(9):1489-97

Izeddin I (2014) Single-molecule tracking in live cells reveals distinct target-search strategies of transcription factors in the nucleus. Elife

Jang M, Cai L, Udeani GO, et al. (1997) Cancer chemopreventive activity of resveratrol, a natural product derived from grapes. Science 275(5297):218-20

Jiang W, Ogretmen B (2014) Autophagy paradox and ceramide. Biochim Biophys Acta 1841(5):783-92

Kaeberlein M, McDonagh T, Heltweg B, et al. (2005) Substrate-specific activation of sirtuins by resveratrol. J Biol Chem 280(17):17038-45

Kalvodova L, Kahya N, Schwille P, et al. (2005) Lipids as modulators of proteolytic activity of BACE: involvement of cholesterol, glycosphingolipids, and anionic phospholipids in vitro. J Biol Chem 280(44):36815-23

Kamath-Loeb AS, Balakrishna S, Whittington D, et al. (2014) Sphingosine: A Modulator of Human Translesion DNA Polymerase Activity. J Biol Chem

Karliner JS (2013) Sphingosine kinase and sphingosine 1-phosphate in the heart: a decade of progress. Biochim Biophys Acta 1831(1):203-12

Khurana S, Venkataraman K, Hollingsworth A, Piche M, Tai TC (2013) Polyphenols: benefits to the cardiovascular system in health and in aging. Nutrients 5(10):3779-827

Kim DH, Kim SH, Kim HJ, Jin C, Chung KC, Rhim H (2010) Stilbene derivatives as human 5-HT(6) receptor antagonists from the root of Caragana sinica. Biol Pharm Bull 33(12):2024-8

Kim RH, Takabe K, Milstien S, Spiegel S (2009) Export and functions of sphingosine-1-phosphate. Biochim Biophys Acta 1791(7):692-6

Kucuksayan E, Konuk EK, Demir N, Mutus B, Aslan M (2014) Neutral sphingomyelinase inhibition decreases ER stress-mediated apoptosis and inducible nitric oxide synthase in retinal pigment epithelial cells. Free Radic Biol Med 72C:113-123

Kueck A, Opipari AW, Jr., Griffith KA, et al. (2007) Resveratrol inhibits glucose metabolism in human ovarian cancer cells. Gynecol Oncol 107(3):450-7

Kulanthaivel P, Janzen WP, Ballas LM, et al. (1995) Naturally occurring protein kinase C inhibitors; II. Isolation of oligomeric stilbenes from Caragana sinica. Planta Med 61(1):41-4

Kunkel GT, Maceyka M, Milstien S, Spiegel S (2013) Targeting the sphingosine-1-phosphate axis in cancer, inflammation and beyond. Nat Rev Drug Discov 12(9):688-702 
Kurano M, Hara M, Tsuneyama K, et al. (2014) Induction of insulin secretion by apolipoprotein M, a carrier for sphingosine 1-phosphate. Biochim Biophys Acta

Kushiro T, Nambara E, McCourt P (2003) Hormone evolution: The key to signalling. Nature 422(6928): 122

Langcake P, Pryce RJ (1977a) A new class of phytoalexins from grapevines. Experientia 33(2):151-2

Langcake P, Pryce RJ (1977b) The production of resveratrol and the viniferins by grapevines in response to ultraviolet irradiation. Phytochemistry 16(8):1193-6

Lavieu G, Scarlatti F, Sala G, et al. (2006) Regulation of autophagy by sphingosine kinase 1 and its role in cell survival during nutrient starvation. J Biol Chem 281(13):8518-27

Lee SH, Shin NH, Kang SH, et al. (1998) Alpha-viniferin: a prostaglandin H2 synthase inhibitor from root of Carex humilis. Planta Med 64(3):204-7

Leonard SS, Xia C, Jiang BH, et al. (2003) Resveratrol scavenges reactive oxygen species and effects radical-induced cellular responses. Biochem Biophys Res Commun 309(4):1017-26

Li Y, Li S, Qin X, et al. (2014) The pleiotropic roles of sphingolipid signaling in autophagy. Cell Death Dis $5: \mathrm{e} 1245$

Lim KG, Gray AI, Pyne S, Pyne NJ (2012a) Resveratrol dimers are novel sphingosine kinase 1 inhibitors and affect sphingosine kinase 1 expression and cancer cell growth and survival. Br J Pharmacol 166(5):1605-16

Lim KG, Tonelli F, Berdyshev E, et al. (2012b) Inhibition kinetics and regulation of sphingosine kinase 1 expression in prostate cancer cells: functional differences between sphingosine kinase $1 \mathrm{a}$ and $1 \mathrm{~b}$. Int J Biochem Cell Biol 44(9):1457-64

Lim KG, Tonelli F, Li Z, et al. (2011a) FTY720 analogues as sphingosine kinase 1 inhibitors: enzyme inhibition kinetics, allosterism, proteasomal degradation, and actin rearrangement in MCF-7 breast cancer cells. J Biol Chem 286(21):18633-40

Lim KG, Sun C, Bittman R, Pyne NJ, Pyne S (2011b) (R)-FTY720 methyl ether is a specific sphingosine kinase 2 inhibitor: Effect on sphingosine kinase 2 expression in HEK 293 cells and actin rearrangement and survival of MCF-7 breast cancer cells. Cell Signal 23(10):1590-5

Lin HY, Delmas D, Vang O, et al. (2013) Mechanisms of ceramide-induced COX-2-dependent apoptosis in human ovarian cancer OVCAR-3 cells partially overlapped with resveratrol. J Cell Biochem 114(8):1940-54

Liu M, Seo J, Allegood J, et al. (2014) Hepatic apolipoprotein M (apoM) overexpression stimulates formation of larger apoM/sphingosine 1-phosphate-enriched plasma high density lipoprotein. J Biol Chem 289(5):2801-14

Liu Z, MacRitchie N, Pyne S, Pyne NJ, Bittman R (2013) Synthesis of (S)-FTY720 vinylphosphonate analogues and evaluation of their potential as sphingosine kinase 1 inhibitors and activators. Bioorg Med Chem 21(9):2503-10

Loveridge C, Tonelli F, Leclercq T, et al. (2010) The sphingosine kinase 1 inhibitor 2-( $p$-hydroxyanilino)4 -( $p$-chlorophenyl)thiazole induces proteasomal degradation of sphingosine kinase 1 in mammalian cells. J Biol Chem 285(50):38841-52

Maceyka M, Harikumar KB, Milstien S, Spiegel S (2012) Sphingosine-1-phosphate signaling and its role in disease. Trends Cell Biol 22(1):50-60

Maceyka M, Sankala H, Hait NC, et al. (2005) SphK1 and SphK2, sphingosine kinase isoenzymes with opposing functions in sphingolipid metabolism. J Biol Chem 280(44):37118-29

Manna SK, Mukhopadhyay A, Aggarwal BB (2000) Resveratrol suppresses TNF-induced activation of nuclear transcription factors NF-kappa B, activator protein-1, and apoptosis: potential role of reactive oxygen intermediates and lipid peroxidation. J Immunol 164(12):6509-19

Marambaud P, Zhao H, Davies P (2005) Resveratrol promotes clearance of Alzheimer's disease amyloidbeta peptides. J Biol Chem 280(45):37377-82

Mattison JA, Wang M, Bernier M, et al. (2014) Resveratrol prevents high fat/sucrose diet-induced central arterial wall inflammation and stiffening in nonhuman primates. Cell Metab 20(1):183-90

Means CK, Brown JH (2009) Sphingosine-1-phosphate receptor signalling in the heart. Cardiovasc Res 82(2):193-200

Mielke MM, Bandaru VV, Haughey NJ, et al. (2012) Serum ceramides increase the risk of Alzheimer disease: the Women's Health and Aging Study II. Neurology 79(7):633-41

Mielke MM, Lyketsos CG (2010) Alterations of the sphingolipid pathway in Alzheimer's disease: new biomarkers and treatment targets? Neuromolecular Med 12(4):331-40 
Minutolo F, Sala G, Bagnacani A, et al. (2005) Synthesis of a resveratrol analogue with high ceramidemediated proapoptotic activity on human breast cancer cells. J Med Chem 48(22):6783-6

Mobasheri A, Shakibaei M (2013) Osteogenic effects of resveratrol in vitro: potential for the prevention and treatment of osteoporosis. Ann N Y Acad Sci 1290:59-66

Morad SA, Cabot MC (2013) Ceramide-orchestrated signalling in cancer cells. Nat Rev Cancer 13(1):5165

Muhtadi, Hakim EH, Juliawaty LD, et al. (2006) Cytotoxic resveratrol oligomers from the tree bark of Dipterocarpus hasseltii. Fitoterapia 77(7-8):550-5

Neubauer HA, Pitson SM (2013) Roles, regulation and inhibitors of sphingosine kinase 2. FEBS J 280(21):5317-36

Nixon RA (2013) The role of autophagy in neurodegenerative disease. Nat Med 19(8):983-97

Nwachukwu JC, Srinivasan S, Bruno NE, et al. (2014) Resveratrol modulates the inflammatory response via an estrogen receptor-signal integration network. Elife 3:e02057

Obeid LM, Linardic CM, Karolak LA, Hannun YA (1993) Programmed cell death induced by ceramide. Science 259(5102):1769-71

Ohguchi K, Akao Y, Matsumoto K, et al. (2005) Vaticanol C-induced cell death is associated with inhibition of pro-survival signaling in HL60 human leukemia cell line. Biosci Biotechnol Biochem 69(2):353-6

Ohguchi K, Tanaka $\mathrm{T}$, Ito $\mathrm{T}$, et al. (2003) Inhibitory effects of resveratrol derivatives from Dipterocarpaceae plants on tyrosinase activity. Biosci Biotechnol Biochem 67(7):1587-9

Ohyama M, Tanaka T, Ito T, Iinuma M, Bastow KF, Lee KH (1999) Antitumor agents 200. Cytotoxicity of naturally occurring resveratrol oligomers and their acetate derivatives. Bioorg Med Chem Lett 9(20):3057-60

Oi N, Jeong CH, Nadas J, et al. (2010) Resveratrol, a red wine polyphenol, suppresses pancreatic cancer by inhibiting leukotriene A(4)hydrolase. Cancer Res 70(23):9755-64

Olivera A, Spiegel S (1993) Sphingosine-1-phosphate as second messenger in cell proliferation induced by PDGF and FCS mitogens. Nature 365(6446):557-60

Orallo F (2008) Trans-resveratrol: a magical elixir of eternal youth? Curr Med Chem 15(19):1887-98

Park K, Elias PM, Hupe M, et al. (2013) Resveratrol stimulates sphingosine-1-phosphate signaling of cathelicidin production. J Invest Dermatol 133(8):1942-9

Park SJ, Ahmad F, Philp A, et al. (2012) Resveratrol ameliorates aging-related metabolic phenotypes by inhibiting cAMP phosphodiesterases. Cell 148(3):421-33

Patel KR, Andreadi C, Britton RG, et al. (2013) Sulfate metabolites provide an intracellular pool for resveratrol generation and induce autophagy with senescence. Sci Transl Med 5(205):205ra133

Pineda-Sanabria SE, Robertson IM, Sykes BD (2011) Structure of trans-resveratrol in complex with the cardiac regulatory protein troponin C. Biochemistry 50(8):1309-20

Pinho BR, Ferreres F, Valentao P, Andrade PB (2013) Nature as a source of metabolites with cholinesterase-inhibitory activity: an approach to Alzheimer's disease treatment. J Pharm Pharmacol 65(12):1681-700

Poti F, Simoni M, Nofer JR (2014) Atheroprotective role of high-density lipoprotein (HDL)-associated sphingosine-1-phosphate (S1P). Cardiovasc Res

Puglielli L, Ellis BC, Saunders AJ, Kovacs DM (2003) Ceramide stabilizes beta-site amyloid precursor protein-cleaving enzyme 1 and promotes amyloid beta-peptide biogenesis. J Biol Chem 278(22): 19777-83

Puissant A, Robert G, Fenouille N, et al. (2010) Resveratrol promotes autophagic cell death in chronic myelogenous leukemia cells via JNK-mediated p62/SQSTM1 expression and AMPK activation. Cancer Res 70(3):1042-52

Pyne NJ, Pyne S (2010) Sphingosine 1-phosphate and cancer. Nat Rev Cancer 10(7):489-503

Pyne S, Pyne NJ (2000) Sphingosine 1-phosphate signalling in mammalian cells. Biochem J 349(Pt 2):385402

Pyne S, Pyne NJ (2011) Translational aspects of sphingosine 1-phosphate biology. Trends Mol Med 17(8):463-72

Qiao H, Chen X, Xu L, et al. (2013) Antitumor effects of naturally occurring oligomeric resveratrol derivatives. FASEB J 27(11):4561-71 
Qin J, Berdyshev E, Poirer C, Schwartz NB, Dawson G (2012) Neutral sphingomyelinase 2 deficiency increases hyaluronan synthesis by up-regulation of Hyaluronan synthase 2 through decreased ceramide production and activation of Akt. J Biol Chem 287(17):13620-32

Raj P, Louis XL, Thandapilly SJ, Movahed A, Zieroth S, Netticadan T (2014) Potential of resveratrol in the treatment of heart failure. Life Sci 95(2):63-71

Richard T, Pawlus AD, Iglesias ML, et al. (2011a) Neuroprotective properties of resveratrol and derivatives. Ann N Y Acad Sci 1215:103-8

Richard T, Poupard P, Nassra M, et al. (2011b) Protective effect of epsilon-viniferin on beta-amyloid peptide aggregation investigated by electrospray ionization mass spectrometry. Bioorg Med Chem 19(10):3152-5

Roberts VH, Pound LD, Thorn SR, et al. (2014) Beneficial and cautionary outcomes of resveratrol supplementation in pregnant nonhuman primates. FASEB J 28(6):2466-2477

Russo SB, Ross JS, Cowart LA (2013) Sphingolipids in obesity, type 2 diabetes, and metabolic disease. Handb Exp Pharmacol(216):373-401

Sahebkar A (2013) Effects of resveratrol supplementation on plasma lipids: a systematic review and metaanalysis of randomized controlled trials. Nutr Rev 71(12):822-35

Sahidin, Hakim EH, Juliawaty LD, et al. (2005) Cytotoxic properties of oligostilbenoids from the tree barks of Hopea dryobalanoides. Z Naturforsch C 60(9-10):723-7

Sala G, Minutolo F, Macchia M, Sacchi N, Ghidoni R (2003) Resveratrol structure and ceramideassociated growth inhibition in prostate cancer cells. Drugs Exp Clin Res 29(5-6):263-9

Samad F, Hester KD, Yang G, Hannun YA, Bielawski J (2006) Altered adipose and plasma sphingolipid metabolism in obesity: a potential mechanism for cardiovascular and metabolic risk. Diabetes 55(9):2579-87

Santana P, Pena LA, Haimovitz-Friedman A, et al. (1996) Acid sphingomyelinase-deficient human lymphoblasts and mice are defective in radiation-induced apoptosis. Cell 86(2):189-99

Scarlatti F, Maffei R, Beau I, Codogno P, Ghidoni R (2008) Role of non-canonical Beclin 1-independent autophagy in cell death induced by resveratrol in human breast cancer cells. Cell Death Differ 15(8):1318-29

Scarlatti F, Sala G, Ricci C, et al. (2007) Resveratrol sensitization of DU145 prostate cancer cells to ionizing radiation is associated to ceramide increase. Cancer Lett 253(1):124-30

Scarlatti F, Sala G, Somenzi G, Signorelli P, Sacchi N, Ghidoni R (2003) Resveratrol induces growth inhibition and apoptosis in metastatic breast cancer cells via de novo ceramide signaling. FASEB J 17(15):2339-41

Schwalm S, Pfeilschifter J, Huwiler A (2014) Targeting the sphingosine kinase/sphingosine 1-phosphate pathway to treat chronic inflammatory kidney diseases. Basic Clin Pharmacol Toxicol 114(1):44-9

Semba RD, Ferrucci L, Bartali B, et al. (2014) Resveratrol levels and all-cause mortality in older community-dwelling adults. JAMA Intern Med

Seya K, Kanemaru K, Sugimoto C, et al. (2009) Opposite effects of two resveratrol (trans-3,5,4'trihydroxystilbene) tetramers, vitisin A and hopeaphenol, on apoptosis of myocytes isolated from adult rat heart. J Pharmacol Exp Ther 328(1):90-8

Shibata MA, Akao Y, Shibata E, et al. (2007) Vaticanol C, a novel resveratrol tetramer, reduces lymph node and lung metastases of mouse mammary carcinoma carrying p53 mutation. Cancer Chemother Pharmacol 60(5):681-91

Shin KO, Park NY, Seo CH, et al. (2012) Inhibition of sphingolipid metabolism enhances resveratrol chemotherapy in human gastric cancer cells. Biomol Ther (Seoul) 20(5):470-6

Shukla Y, Singh R (2011) Resveratrol and cellular mechanisms of cancer prevention. Ann N Y Acad Sci 1215:1-8

Signorelli P, Ghidoni R (2005) Resveratrol as an anticancer nutrient: molecular basis, open questions and promises. J Nutr Biochem 16(8):449-66

Signorelli P, Munoz-Olaya JM, Gagliostro V, Casas J, Ghidoni R, Fabrias G (2009) Dihydroceramide intracellular increase in response to resveratrol treatment mediates autophagy in gastric cancer cells. Cancer Lett 282(2):238-43

Sim J, Jang HW, Song M, Kim JH, Lee SH, Lee S (2014) Potent inhibitory effect of alpha-viniferin on human cytochrome P450. Food Chem Toxicol 69:276-80

Simbulan CM, Tamiya-Koizumi K, Suzuki M, Shoji M, Taki T, Yoshida S (1994) Sphingosine inhibits the synthesis of RNA primers by primase in vitro. Biochemistry 33(30):9007-12 
Sinclair DA, Guarente L (2014) Small-molecule allosteric activators of sirtuins. Annu Rev Pharmacol Toxicol 54:363-80

Smoliga JM, Vang O, Baur JA (2012) Challenges of translating basic research into therapeutics: resveratrol as an example. J Gerontol A Biol Sci Med Sci 67(2):158-67

Snyder SA, Gollner A, Chiriac MI (2011) Regioselective reactions for programmable resveratrol oligomer synthesis. Nature 474(7352):461-6

Sotheeswaran S, Pasupathy V (1993) Distribution of resveratrol oligomers in plants. Phytochemistry 32(5):1083-92

Strub GM, Paillard M, Liang J, et al. (2011) Sphingosine-1-phosphate produced by sphingosine kinase 2 in mitochondria interacts with prohibitin 2 to regulate complex IV assembly and respiration. FASEB J 25(2):600-12

Subbaramaiah K, Chung WJ, Michaluart P, et al. (1998) Resveratrol inhibits cyclooxygenase-2 transcription and activity in phorbol ester-treated human mammary epithelial cells. J Biol Chem 273(34):21875-82

Sung SH, Kang SY, Lee KY, et al. (2002) (+)-Alpha-viniferin, a stilbene trimer from Caragana chamlague, inhibits acetylcholinesterase. Biol Pharm Bull 25(1):125-7

Szewczuk LM, Forti L, Stivala LA, Penning TM (2004) Resveratrol is a peroxidase-mediated inactivator of COX-1 but not COX-2: a mechanistic approach to the design of COX-1 selective agents. J Biol Chem 279(21):22727-37

Tabata Y, Takano K, Ito T, et al. (2007) Vaticanol B, a resveratrol tetramer, regulates endoplasmic reticulum stress and inflammation. Am J Physiol Cell Physiol 293(1):C411-8

Takasugi N, Sasaki T, Suzuki K, et al. (2011) BACE1 activity is modulated by cell-associated sphingosine1-phosphate. J Neurosci 31(18):6850-7

Tanaka T, Ito T, Ido Y, et al. (2000) Stilbenoids in the stem bark of Hopea parviflora. Phytochemistry 53(8):1015-9

Timmers S, Hesselink MK, Schrauwen P (2013) Therapeutic potential of resveratrol in obesity and type 2 diabetes: new avenues for health benefits? Ann N Y Acad Sci 1290:83-9

Tome-Carneiro J, Gonzalvez M, Larrosa M, et al. (2013) Resveratrol in primary and secondary prevention of cardiovascular disease: a dietary and clinical perspective. Ann N Y Acad Sci 1290:37-51

Trincheri NF, Follo C, Nicotra G, Peracchio C, Castino R, Isidoro C (2008) Resveratrol-induced apoptosis depends on the lipid kinase activity of Vps34 and on the formation of autophagolysosomes. Carcinogenesis 29(2):381-9

Tsukamoto T, Nakata R, Tamura E, et al. (2010) Vaticanol C, a resveratrol tetramer, activates PPARalpha and PPARbeta/delta in vitro and in vivo. Nutr Metab (Lond) 7:46

Uchida Y (2014) Ceramide signaling in mammalian epidermis. Biochim Biophys Acta 1841(3):453-62

Ulrich S, Huwiler A, Loitsch S, Schmidt H, Stein JM (2007) De novo ceramide biosynthesis is associated with resveratrol-induced inhibition of ornithine decarboxylase activity. Biochem Pharmacol 74(2):281-9

Urs AN, Dammer E, Sewer MB (2006) Sphingosine regulates the transcription of CYP17 by binding to steroidogenic factor-1. Endocrinology 147(11):5249-58

Vingtdeux V, Dreses-Werringloer U, Zhao H, Davies P, Marambaud P (2008) Therapeutic potential of resveratrol in Alzheimer's disease. BMC Neurosci 9 Suppl 2:S6

Waeber C, Walther T (2014) Sphingosine-1-phosphate as a potential target for the treatment of myocardial infarction. Circ J 78(4):795-802

Wang J, Bi W, Cheng A, et al. (2014) Targeting multiple pathogenic mechanisms with polyphenols for the treatment of Alzheimer's disease-experimental approach and therapeutic implications. Front Aging Neurosci 6:42

Wang Z, Min X, Xiao SH, et al. (2013) Molecular basis of sphingosine kinase 1 substrate recognition and catalysis. Structure 21(5):798-809

Waters CM, Long J, Gorshkova I, et al. (2006) Cell migration activated by platelet-derived growth factor receptor is blocked by an inverse agonist of the sphingosine 1-phosphate receptor-1. FASEB J 20(3):509-11

Weber J, Wahab I, Marzuki A, et al. (2001) Heimiol A, a new dimeric stilbenoid from Neobalanocarpus heimii. Tetrahedron Lett 42(29):4895-97 
Weiler S, Braendlin N, Beerli C, et al. (2014) Orally active 7-substituted (4-Benzylphthalazin-1-yl)-2methylpiperazin-1-yl]nicotinonitriles as active-site inhibitors of sphingosine 1-phosphate lyase for the treatment of multiple sclerosis. J Med Chem

Widlund AL, Baur JA, Vang O (2013) mTOR: more targets of resveratrol? Expert Rev Mol Med 15:e10

Worrall D, Liang YK, Alvarez S, et al. (2008) Involvement of sphingosine kinase in plant cell signalling. Plant J 56(1):64-72

Wu JM, Hsieh TC, Yang CJ, Olson SC (2013) Resveratrol and its metabolites modulate cytokine-mediated induction of eotaxin-1 in human pulmonary artery endothelial cells. Ann N Y Acad Sci 1290:30-6

Xu G, Zhang LP, Chen LF, Hu CQ (1994) Inhibition of protein kinase C by stilbenoids. Yao Xue Xue Bao 29(11):818-22

Yamada M, Hayashi K, Ikeda S, et al. (2006) Inhibitory activity of plant stilbene oligomers against DNA topoisomerase II. Biol Pharm Bull 29(7):1504-7

Yan KX, Terashima K, Takaya Y, Niwa M (2001) A novel oligostilbene named (+)-viniferol A from the stem of Vitis vinifera 'kyohou'. Tetrahedron 57(14):2711-15

Yan R, Vassar R (2014) Targeting the beta secretase BACE1 for Alzheimer's disease therapy. Lancet Neurol 13(3):319-29

Yan T, Wang T, Wei W, et al. (2012) Polyphenolic acetylcholinesterase inhibitors from Hopea chinensis. Planta Med 78(10):1015-9

Zetterstrom CE, Hasselgren J, Salin O, et al. (2013) The resveratrol tetramer (-)-hopeaphenol inhibits type III secretion in the gram-negative pathogens Yersinia pseudotuberculosis and Pseudomonas aeruginosa. PLoS One 8(12):e81969

Zgoda-Pols JR, Freyer AJ, Killmer LB, Porter JR (2002) Antimicrobial resveratrol tetramers from the stem bark of Vatica oblongifolia ssp. oblongifolia. J Nat Prod 65(11):1554-9

Zykova TA, Zhu F, Zhai X, et al. (2008) Resveratrol directly targets COX-2 to inhibit carcinogenesis. Mol Carcinog 47(10):797-805 